University of Redlands

\title{
Identifying Target Markets for Spanish Language Publications in Southern California
}

A Major Individual Project submitted in partial satisfaction of the requirements

for the degree of Master of Science in Geographic Information Systems

\author{
by \\ Noor Yusuf Najem Yusuf \\ Ren Fang, Ph.D., Committee Chair \\ Mark Kumler, Ph.D.
}

December 2010 
Identifying Target Markets for Spanish Language Publication in Southern California

Copyright $@ 2010$

by

Noor Yusuf Najem Yusuf 
The report of Noor Yusuf Najem Yusuf is approved.

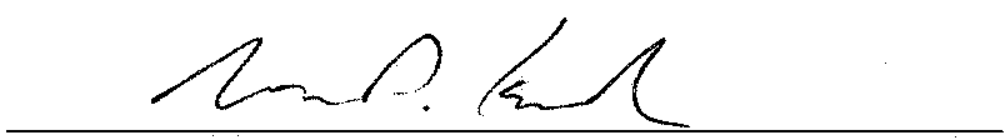

Mark Kumler, Ph.D.

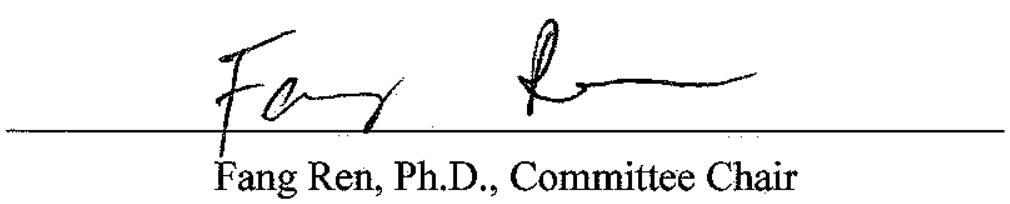

December 2010 



\section{Acknowledgments}

Thank you Allah for all the graces and success, I would not be able to finish this project without your will.

I would like to thank His Excellency the Minister of Interior-Kingdom of Bahrain, Sheikh Rashid bin Abdulla Al-Khalifa, Major-General Team Abdullatif Al-Zayani- Chief of public security prior, Major-General Basim Al-Hamer- President of Customs, Lt. Col

Waleed Al-Hamden - Director of Works Directorate for the great opportunity and guidance that enabled me to study Masters in Science in Geographic Information System at University of Redlands- USA.

I would like to thank Mr. Jack Dangermond Esri founder and president for his support.

I would like also to thank the University of Redlands and the faculty for the full support and guidance that enabled me to accomplish this project, especially the diligent and smart advisor Fang Ren, Ph.D for her guidance and efforts.

I would like to thank Debra Riley, Program Coordinator for all that she did for me that helped me going through. I also want to thank Ruben Ortiz for his support and I want to thank all the Redlands Institute staff for their assistance during critical stages of this project, especially Serene Ong.

To my parents, thank you for your unconditional support and unlimited love. Thank you for your prayers I'm honored to have you as my parents. To the person who believed in

me, thank you for allowing me to further my studies. Please do not ever doubt my dedication and love for you. To my family, thank you for all support. To the person who helped me to go through all the bumps and was patient with me, my brother Mohammed Alsharif. To the Singapore sister Michelle for being there for me, thank you.

To Mr. Ahmed Redah, Mr. Ahmed AlAwady, Mr. Mahmood Alsayed, and Mr. Ahmed Sherif who helped me develop my GIS foundation and all ESRINeA team. To my friends: Walla, Renee, Anne for your support. To Cohort 17 who made this year pass quickly and it was an interesting learning year.

To the International Friendship connection, Aseel, and Ali, thank you for helping me in Redlands.

Thank you All 



\begin{abstract}
Identifying Target Markets for Spanish Language Publication in Southern California

by

Noor Yusuf Najem Yusuf
\end{abstract}

The Press-Enterprise is a publisher in Riverside County, California, which traces its roots to 1878 . The Press-Enterprise began publishing daily sports news, local news, community events, and more. One of their products is the Spanish newspaper La Prensa, which is an information source for the Inland Empire's Hispanic community. La Prensa is available weekly and for free. Currently the newspaper is distributed through more than two thousands news racks and stores in the three different counties: Riverside, Los Angeles, and San Bernardino. In order to increase the number of subscribers for La Prensa, the marketing department of Press-Enterprise needed to know where the market is for the highest proportion of distribution of the Spanish newspapers to introduce home delivery for the Spanish product. Thus, the client needed to perform analysis to identify good market areas for home delivery of La Prensa. The Identifying Target Markets for Spanish Language Publication in southern California (ITMSLP) project helped to identify the neighborhoods where there is a Hispanic concentration. A Trade area analysis used to show the current distribution and aggregate the demographic information for the distributions' neighborhoods. Also, regression model was built to estimate the potentials of acceptance of home delivery of the newspaper and Find Similar analysis was conducted to show the recommended block groups for distribution. The final results were delivered to the client in the form of hard-copy maps and an online mapping application. 



\section{Table of Contents}

Chapter 1 - Introduction ................................................................................................ 1

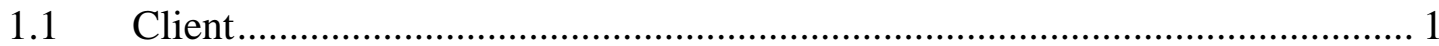

$1.2 \quad$ Problem Statement ................................................................................ 1

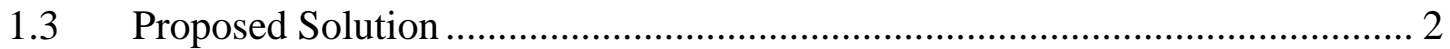

1.3.1 Goals and Objectives ............................................................................. 2

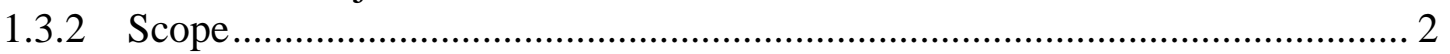

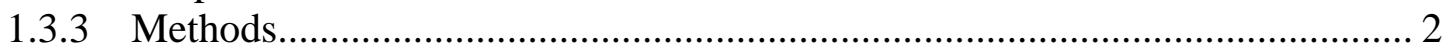

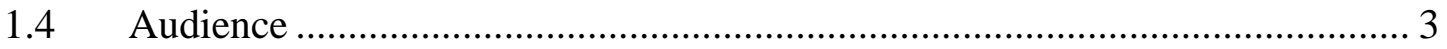

1.5 Overview of the Rest of This Report ............................................................ 3

Chapter 2 - Background and Literature Review ............................................................... 5

$2.1 \quad$ Application of GIS in Marketing ……………….................................. 5

2.1.1 Overview of GIS application in Marketing …………................................ 5

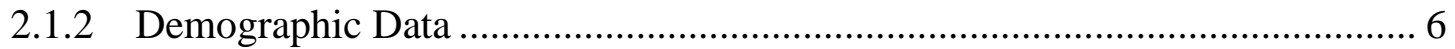

2.2 GIS Analysis Tools in Marketing ......................................................... 7

2.2.1 Geodemographic Profiling ................................................................. 7

2.2.2 Trade Area Analysis ............................................................................. 7

2.2.3 Regression Analysis in Marketing ……………..................................... 9

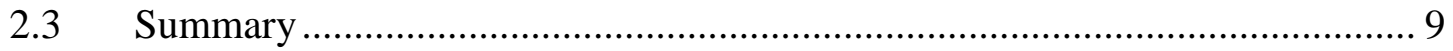

Chapter 3 - Systems Analysis and Design......................................................................... 11

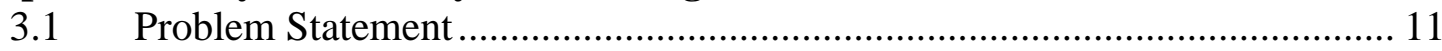

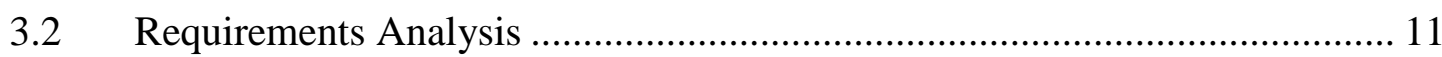

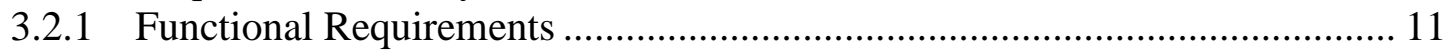

3.2.2 Non-Functional Requirements …………………..................................... 12

3.3 System Design ................................................................................... 13

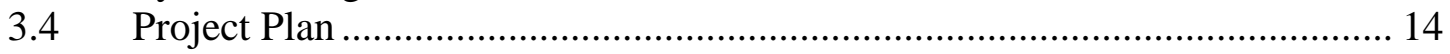

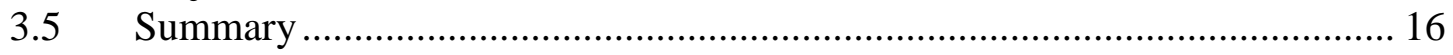

Chapter 4 - Database Design................................................................................................... 17

$4.1 \quad$ Conceptual Data Model ...................................................................... 17

4.2 Logical Data Model .............................................................................. 17

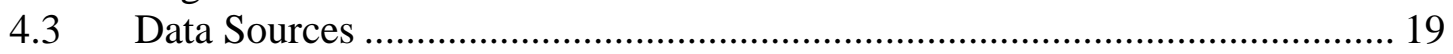

4.3.1 Client Data ……….............................................................................. 19

4.3.2 ESRI Business Analyst Data................................................................. 19

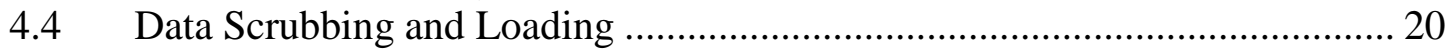

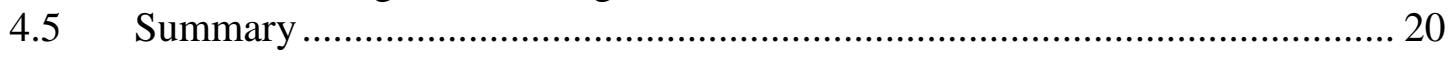

Chapter 5 - Implementation................................................................................... 21

5.1 Analyzing the Relationship between Neighborhood Characteristics and $\mathrm{La}$

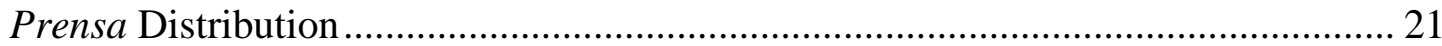

5.1.1 Finding Trade Area of Store Clusters ........................................................... 21

5.1.2 Examining Neighborhood Demographic Characteristics ………………….... 23

5.1.3 Find Similar Neighborhoods..................................................................... 24

$5.2 \quad$ Building Web Application ................................................................... 24

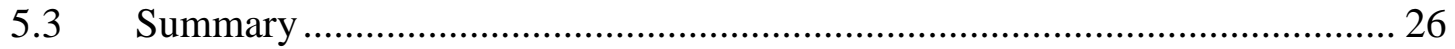


Chapter 6 - Results and Analysis........................................................................... 27

6.1 Relationship Between Neighborhood Characteristics and La Prensa

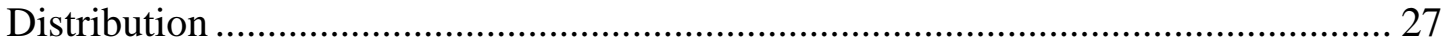

6.1.1 Trade Areas of Store Clusters ............................................................... 27

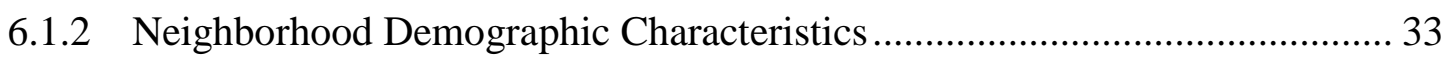

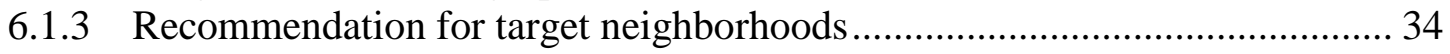

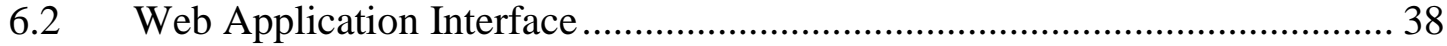

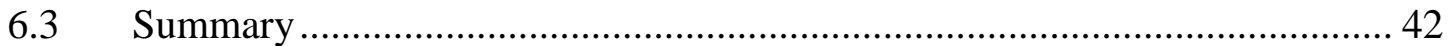

Chapter 7 - Conclusions and Future Work ......................................................... 43

7.1 Find Target Location for La Prensa Distribution Conclusions ...................... 43

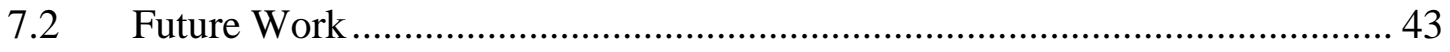

Works Cited 45

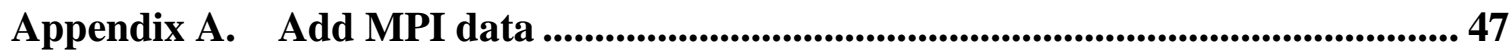

Appendix B. Script codes “ Find Multiple Mean Center Iteration Python code and

Delete Duplicate Python code " .............................................................................................. 49

Appendix C. Riverside County Sample of Recommended Block Groups for La

Prensa Distribution ...................................................................................................5 53

Appendix D. Los Angeles County Sample of Recommended Block Groups for La

Prensa Distribution ...................................................................................................... 55

Appendix E. San Bernardino County Sample of Recommended Block Groups for

La Prensa Distribution.......................................................................................................... 57 


\section{Table of Figures}

Figure 2-1: Center Point Method ............................................................................. 8

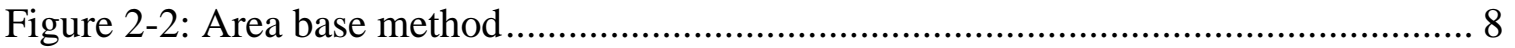

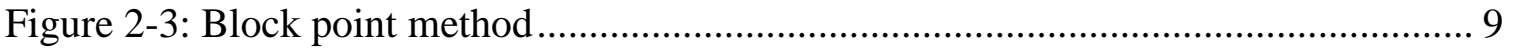

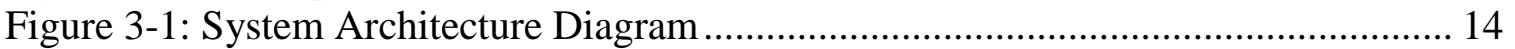

Figure 3-2: Executing Phase Diagram - Collect and Work with Data ............................ 15

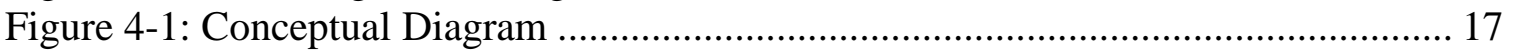

4-2 Logical Diagram - Feature Class Attributes ......................................................... 18

Figure 5-1: Analyzing Relationship Between Neighborhood Characteristics and La

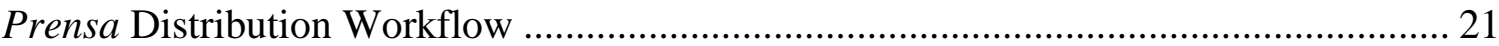

Figure 5-2: Web Application Interface Design............................................................. 25

Figure 6-1 La Prensa Store Clusters by Business Analyst and Find Mean Center

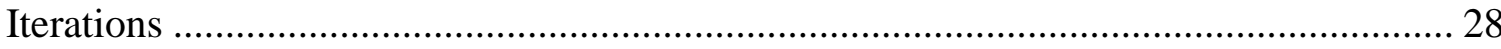

Figure 6-2: Trade Areas Based on Business Analyst Mean Center................................. 30

Figure 6-3: Trade Areas Based on Find Mean Center Iterations .................................... 32

Figure 6-4: Targeted Areas for La Prensa Distribution, Riverside County .................... 35

Figure 6-5: Targeted Areas for La Prensa Distribution, Los Angeles County ................. 36

Figure 6-6: Targeted Areas for La Prensa Distribution, San Bernardino County ............ 37

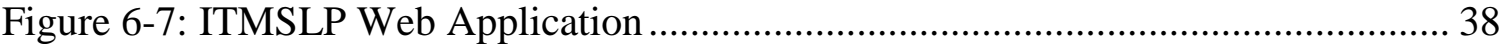

Figure 6-8: Table of Contents Tool and Legend............................................................ 39

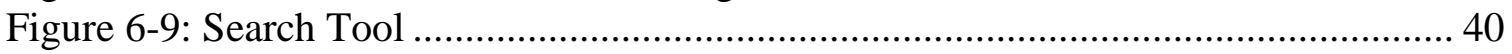

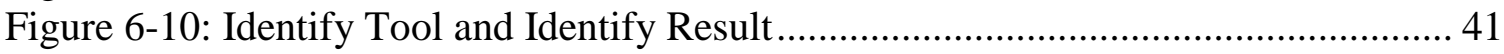

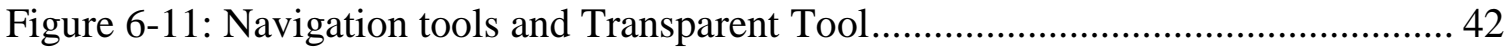





\section{List of Tables}

Table 1. System Functions ................................................................................ 12

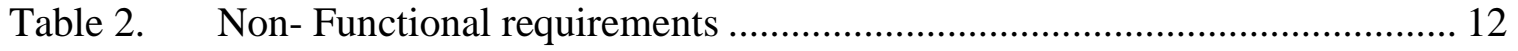

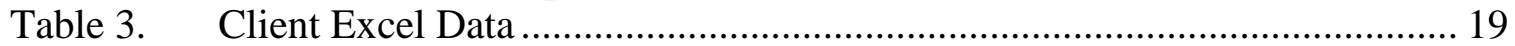

Table 4. Variables Involved in Exploratory Stage in Regression .............................. 23

Table 5. Linear Regression Model Result............................................................. 34 



\section{List of Acronyms and Definitions}

ITMSLP Identify Target Markets for Spanish Language Publications

GIS Geographic Information System

DOMTAP Dominant Tapestry Code

MPI Market Potential Indexes

DRAW Number of newspaper placed on news rack or stores

WBS Work Breakdown Structure

WBS is subdividing the major project deliverables and project work into smaller more manageable components. Used to organize and define the total scope of the project during planning. 



\section{Chapter 1 - Introduction}

Every newspaper firm tends to ask basic questions to locate their customers like "who are the customers?", "where do they locate?", and "how to find them?". The answers to these questions help them set their strategic plans to target their customers and thus to increase their distribution and sales in newspaper industry. Many media marketing departments have been using geographic information system (GIS) to map demographics and the locations of viewers or subscribers. The Press-Enterprise, a publisher in southern California, has also attempted to use mapping techniques to locate their customers, however, with limited success due to the shortage of expertise. The publisher wanted to introduce home delivery for La Prensa, a Spanish-language newspaper, and increase the subscription. But they needed to know who reads the newspaper, where these readers are located, and the best method to reach them. Therefore, this project conducted a series of analyses to identify the markets for Spanish publications in three counties of southern California: San Bernardino, Los Angeles, and Riverside. In this report, this project will be referred as ITMSLP standing for Identifying Target Markets for Spanish Language Publications.

\subsection{Client}

The client for this project was the Press-Enterprise. It is a publisher in the Riverside County, California, which traces its roots to 1878, when Riverside pharmacist and teacher James H. Roe published a weekly paper called The Press. Seven years later, the PressEnterprise began publishing daily sports news, local news, community events, and more. Today, the Press-Enterprise is the largest newspaper in the Inland Empire of southern California, publishing eight products tailored to particular regions in the Riverside County (Enterprise Media, 2010).

One of their products is the Spanish newspaper La Prensa, which is an information source for the Inland Empire's Hispanic community. La Prensa was launched on February 13, 1999, and is available weekly and for free. Currently the newspaper is distributed through more than two thousands news racks and stores in the three different counties: Riverside, Los Angeles, and San Bernardino (Enterprise, 2010). The point of contact of this project was Karen Kokiko, who is the VP of Marketing. She is responsible for defining the appropriate marketing organization for the company, customer segment selection, and related product positioning.

\subsection{Problem Statement}

The client has used different ways to introduce the home delivery for La Prensa in the target areas. For example, the client used random and guesswork methods by selecting random areas to distribute the Spanish newspaper for each home in that area. However, they received many complaints from residents who do not read Spanish newspapers, which led them to look for a better approach. In order to increase the number of subscribers for La Prensa, the marketing department needed to know where the best markets are for the distribution of Spanish newspapers. Understanding the potential 
customers' profile is also essential to the success in selling home delivery subscriptions for the Spanish product. Thus, the client needed to perform analysis to identify the good market areas for home delivery of La Prensa.

\subsection{Proposed Solution}

The ITMSLP project helped to identify the neighborhoods where there is a Hispanic concentration. A regression model was built to estimate the potentials of acceptance of home delivery of the newspaper. Various variables, including income, newspaper reading, education level, and the concentration of adult males, were included in the model and the final results were delivered to the client in form of hard-copy maps and an online mapping application.

\subsubsection{Goals and Objectives}

The goal of the ITMSLP project was to help to inform and refine the current distribution of La Prensa. Specifically, the first objective of ITMSLP project was to provide the client with a series of analyses to show the trade areas of current newspaper distributors, and to predict the best marketing locations using the demographic data. The second objective was to show these maps in more efficient ways, particularly the user should be able to interact with the data and see the final maps in good quality. To this end, a web application was implemented to enable the user to select and search for specific locations, display the demographic information for a selected area, and read the result clearly.

\subsubsection{Scope}

The study area of this project consisted of three counties in southern California: San Bernardino, Los Angeles, and Riverside. Although the map display in the final web application included five counties, including Orange and San Diego counties, the analysis was confined to the data for these three counties. This project relied on the demographic data provided by Esri's Business Analyst, and the data provided by the client, like the ZIP codes that they distribute the product in, and the store location with the level of sales. The project deliverables include the maps showing the target market for the Spanish publication and the locations of current and potential distribution sites, and a web application that the client can use to interact with the maps. The web application provided the client with a clear picture of the Hispanic demographic data and the target locations.

\subsubsection{Methods}

This project followed the waterfall methodology, starting from collecting client requirements, analyzing the requirements, searching for suitable data, working with different analyses, and evaluating the output. As defined by Shewhart in 1950, "Plan Do- Check and Act" cycle (Project Management Institute, 2004) were the main steps that the ITMSLP project followed in each phase of the waterfall model. Project development moved from concept, through design, implementation, testing, installation, troubleshooting, and ended at operation and maintenance; there was no overlap between these phases. 
There were a few analytical methods applied in this study. First, a cluster analysis was conducted to identify how many clusters existing in the current newspaper distributors (the stores where the newspaper were distributed for free). Second, a trade area analysis was performed to locate the customers for each distribution cluster along with overlay analysis to aggregate the demographic data for each trade area. Third, a regression analysis model was built to examine the variables that influence the amount of distributions of the newspaper. Finally, the distribution prediction was made for each census block group using Find Similar analysis. This result was then used to predict residents' willingness to accept home delivery.

\subsection{Audience}

This paper addresses the needs of a newspaper's marketing department, and its Spanishlanguage media strategic planners, to target their customers using demographic data and GIS. Most of the analysis results used Business Analyst data (demographic and ESRI Tapestry segmentation) with marketing analysis methodologies, and displayed the maps in a simple web application. Marketing and Spanish-language publication teams may be interested in using the analysis results through the web.

\subsection{Overview of the Rest of This Report}

This paper contains six chapters. Chapter Two is the literature review which provides background for the project and reviews about similar analyses and projects from different sources. Chapter Three is the system analysis and design for the project. Four is more data related and database design and goes through the process of preparing the data used in this project. Chapter Five covers the actual work and the implementation; with the final results in Chapter Six. Chapter Seven is the final conclusion and future work suggestions. 


\section{Chapter 2 - Background and Literature Review}

The primary purpose of the ITMSLP project is to provide the client with a clear idea of the market and help them to decide where to offer home delivery for the SpanishLanguage products. The client has used different ways to reach and cover most of the target locations, from guesswork to targeting the ZIP codes with high percentages of Hispanics. Given the failure of the previous attempts, the company needed to know the target locations where the home delivery of La Prensa is more likely to be accepted. This project focused on using demographic data to find neighborhoods whose residents mirror a target customer. This chapter introduces the idea of using the demographic data in marketing and different analysis that can be used to identify the target market with some case studies.

\subsection{Application of GIS in Marketing}

The primary focus for all direct marketers is the customers: how to identify them, reach them, keep them, and find more like them. To succeed in reaching these goals there must be an understanding of customers' demographics, behaviors, and buying patterns, because this will increase chances of retaining them and finding more like them. The spatial technologies have grown in the business world. For example, consumer service, billboard advertising, newspaper, and retail are industries that often serve their customer directly with GIS (Pick, 2007). These GIS applications in marketing often rely on demographic data and Community Tapestry data.

\subsubsection{Overview of GIS application in Marketing}

Customers have addresses, preferences, and patterns. Newspaper distribution has geographic coverage area. Therefore, locational information is very important to locate stores and customers. Understanding the spatial dimension of marketing and marketing analysis can improve a firm's ability to serve their customers. Since GIS has the strength in managing, analyzing, and displaying spatial data, the marketing managers who use these tools will be more successful. GIS tools and analysis are vast, but provide four essential capabilities relating to marketing (Miller, 2007):

- Enhanced spatial insight and understanding into marketing which help marketer to better understand their market. For example the World Treasures, functional online stores, defined market segments and assigned them to ZIP codes, created segments for their subscriber profiles, and, finally, display it on maps to get better information on the geographic concentration of attractive ZIP codes.

- Greater potential for visualization in marketing analysis by exploring demographic characteristics, analyzing this data by creating a buffer around each distribution store, and then comparing the market area characteristics. Finally displaying the result in map with graphics shows the characteristics for each area, like the Meiers Home Furnishings, a fictional firm.

- The addition of powerful spatial analysis tools. In some cases the spatial dimension can be analyzed to get more information. For example Outdoor Living 
Inc, a fictional company, had an inherently spatial problem about how to identify the locations that provide high concentrations of the firm's targeted families.

- Enhance communication capabilities in marketing reports and presentation. This is extension of the visualization discussed above. Maps, text, tables, and charts allow better communicating and interacting within analysis results.

\subsubsection{Demographic Data}

Data are important to start any analysis. Demographic data have played a key role in shaping the housing market boom that began in the mid-1990s (Peters \& MacDonald, 2004). In fact, since the 1990 census, GIS has been a necessary tool for any significant census analysis. It became more powerful and easier to use because it is connected directly with census data. Census data can now be incorporated into GIS with other data sources. For instance, by mapping census data, demographers can identify census tracts with high concentrations of elderly residents. Market researchers can find neighborhoods whose residents mirror a target customer's profile. Journalists used census data to find compelling stories. For example, Herzog (2003) analyzed the census data at census tract level and used the Associated Press Census 2000 website to target customer profile. Many other newspapers continue to use the census data to help them with their business. Similarly in journalism marketing, there are many case studies that show how journalists use the census data in investigative reporting (Herzog, 2003). Also, Washington Times case study that uses the GIS to increase subscription rate of daily newspapers (ESRI, 2005). The Washington Times chose Esri's ArcGIS Business Analyst software integrated with Esri's demographic data to refine the subscriber and reader profiles. They appended Tapestry segmentation codes to each subscriber record by ZIP code. These targeted ZIP codes were then aggregated into one of the 65 Tapestry segments based on demographic variables such as age, income, home value, occupation, household type, education, and other consumer behavior characteristics. A few newspapers have mapped the population data by race (Herzog, 2003).

Outsides the United States, demographic data have been used as well to improve decision-making process. For example, UM CURIOUS MINDS and MINDSHARE are two media strategic planner companies in the Kingdom of Bahrain and the Middle East that have agreed on the importance of knowing the demographic data for target locations. Demographic data are used to set the advertisement plan or set the distribution for certain advertisement in newspapers. Kazem (2010) classified the different Bahrainis newspapers by using the Census data:

- Akhbar-Alkahleej Arabic newspaper targets Arabic readers, age of 50 years and above.

- Al-Ayam Arabic newspaper targets Arabic readers, age from 30 to 50 years.

- Gulf Daily News (GDN), an English newspaper, targets non Arabic readers, and so on.

In addition to the census data, Community Tapestry data, provided by Esri, is another important demographic data source for many GIS applications. Tapestry Segmentation systems operate on the theory that people with similar tastes, lifestyles, and behaviors seek others with the same tastes- "like seeks like." These behaviors can be measured, predicted, and targeted. ESRI's Tapestry Segmentation system combines the 
"who" of lifestyle demographics with the "where" of local neighborhood geography to create a model for various lifestyle classifications or segments of actual neighborhoods with addresses - distinct behavioral market segments. Specifically,

"Tapestry Segmentation represents the fourth generation of market segmentation systems that began 30 years ago. The 65-segments Tapestry Segmentation system classifies U.S. neighborhoods based on their socioeconomic and demographic compositions. The power of Tapestry Segmentation allows you to profile consumers in a number of ways including, standard geographic areas including census tract, block group, ZIP Code, and ZIP+4, user-defined areas such as rings or polygons based on distance, drive time, or other specifications, customer addresses or site locations The versatility of Tapestry Segmentation provides several methods of dividing the 65 segments into summary groups for a broader view of U.S. neighborhoods, life-Mode: 12 summary groups based on lifestyle and life-stage, urbanization: 11 summary groups based on geographic and physical features along with income" (ESRI, 2009a, page 3).

\subsection{GIS Analysis Tools in Marketing}

There are a variety of methods that can help firms know more about their customers and predict customer behavior. Profiling customers is one of the methods used to target customers. Segmenting customers or grouping the customers into segment by common characteristics, helps to acquire and retain customers. Profiling customers helps to analyze and target customers. Although there are different methods for marketing, only four relevant analyses are discussed in this section.

\subsubsection{Geodemographic Profiling}

Geodemographic profiling is a method for inferring socioeconomic and demographic characteristics of people based on where they live. Geodemographic profiling is a technique that helps in developing demographic analysis and obtaining demographic characteristics for an area. The technique is based on the premise that populations tend to cluster geographically into groups with relatively similar socioeconomic, demographic, and lifestyle characteristics. This technique looks for similarities and differences rather than precise measures of population characteristics. Geodemographic profiling works better in small size of a geographic unit or area because it actually generalizes the different personal characteristics. The degree of homogeneity among the households in a block group of 500 households is likely to be higher than in a census tract of 1,400 households or ZIP code of 12,000 households. Therefore, the block group offers a better scale at which geodemographic profiling can work (Miller, 2007).

\subsubsection{Trade Area Analysis}

Market analysis often proceeds by first calculating the trade area, then calculating competitive supply. Trade area is defined by several ways. The simplest way of defining it is by assuming the customer will select the nearest store for them to pick the newspapers. Trade area may also be defined as consumer concentration, which is not a measure of convenience. Once market area is defined by one of the methods above, 
demographic characteristics of the target customers can be analyzed by aggregating the data within the trade area.

ESRI Business Analyst provides advance methods to aggregate data within a trade area (ESRI, 2009c):

- Center point method (all or nothing approach). This method aggregates the data of the center point of a block group only if the trade area contains that point, even though only part of the block group may be within the trade area (Figure 2-1).

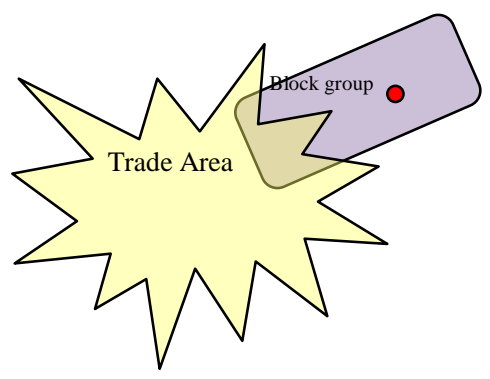

\section{Figure 2-1: Center Point Method}

- Area base method. This method depends on proportion of the block group area covered by the trade area. Although this method is more accurate than the center point method, it assumes that population is uniformly distributed which is not always true. It might calculate 40 percent from the population in the block group, but in reality 40 percent of the population is not in the area covered by trade area, so the result will be less accurate (Figure 2-2).

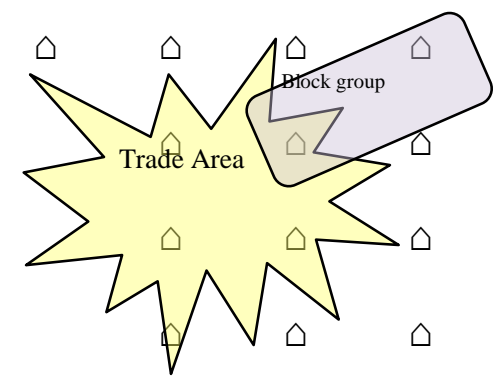

Figure 2-2: Area base method

- Block point method is the default option in Business Analyst. This is the most accurate method, which is based on the smallest geography, the census block point. Block points are the centroids of city blocks. It does not just give the exact population, but also analyzes if the population is based on total household units or total population (Figure 2-3). Only small subsets of data (households, population, housing units, and number of businesses) are available at the Block points. 


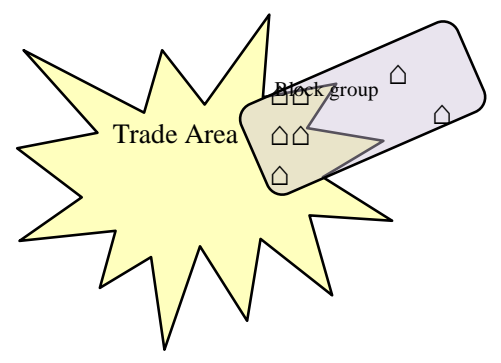

\section{Figure 2-3: Block point method}

Sarkar and Greene (2009) case study focused on the distribution strategy of a Spanishlanguage bridal magazine launched a small business firm based in southern California. Management's objectives included increase circulation, development of a nationwide marketing strategy, and position the magazine as a brand name product in order to attract a committed roster of advertisers. Trade area analysis has been used to investigate the magazine's current distribution and compute accessibility of existing magazine distributors in relation to neighboring population centers. Trade area analysis has been applied using a one mile buffer for each distribution point and aggregate (a) number of distribution centers (b) average Hispanic population, and (c) average median age of Hispanic population for BODAS La Revista USA combining insights into consumer behavior. Geodemographic analysis was conducted to gain insights into customer characteristics in magazine distributor trade areas.

\subsubsection{Regression Analysis in Marketing}

Regression analysis is another method often used to identify the relationships between demographic characteristics and readership or sales of products. For example, Malthouse and Calder (2006) conducted a study on one hundred and one different newspapers and markets. This study finds the strongest predictors of readership are length of residence and age in most markets. Income also has a highly significant positive overall effect. The effect of education is small, but varies across newspapers markets. The fraction of variation in readership accounted for by demographics is small, showing that newspapers have a broad reach across demographic groups.

Another example was by George and Waldfogel (2003). In the study, the analysis focused on the readership and race. The results showed that black people are most likely to purchase a daily newspaper in markets with larger black populations, and blacks are less likely to purchase a paper in a market with a larger white population. The similar pattern was found for Hispanic and non-Hispanic populations.

\subsection{Summary}

Demographic data are the key for marketing analysis and targeting the best customers. There are many different analysis tools used in the marketing field. Selecting the appropriate tool depends on the availability of the data and the application. In this paper, trade area analysis and regression analysis have been selected to solve the client's problem by using both demographic data at the block group level and the Community Tapestry data. Analysis output and maps need a platform to display and since the spatial 
technologies have grown in the business world, the newer technology platforms have involved, in particular the web integration platform. The web services platform encourages greater direct contact, without intermediaries, between the user and the product or service. In addition, this trend is also consistent with finding that the webservices platforms are beneficial (Pick, 2007). This project focused on analytical maps displayed in a web application, where viewing and searching for information is more effective and easy than in a hard copy map. 


\section{Chapter 3 - Systems Analysis and Design}

This chapter discusses user's needs, functional and non-functional requirements, and system design. A detailed functional specification defines the full set of system capabilities to be implemented. The system architecture shows how the system addresses the client's needs by using GIS capabilities and the web technology to examine customer profiles, estimate the best location to target the customers, and represent the final results in an interactive mapping environment.

\subsection{Problem Statement}

The client has used different ways to introduce the home delivery for La Prensa in the target areas. For example, the client used random and guesswork methods by selecting random areas to distribute the Spanish newspaper for each home in that area. However, they received many complaints from residents who do not read Spanish newspapers, which led them to look for a better approach. In order to increase the number of subscribers for La Prensa, the marketing department needed to know where the best markets are for the distribution of Spanish newspapers. Understanding the potential customers' profile is also essential to the success in selling home delivery subscriptions for the Spanish product. Thus, the client needed to perform analysis to identify the good market areas for home delivery of La Prensa.

\subsection{Requirements Analysis}

After several meetings with the client, details were identified to help specify the requirements to meet their needs. As a result, functional requirements and non functional requirements have been listed.

\subsubsection{Functional Requirements}

A function requirement is the approach taken to reach the desired result. The system functional requirements that are extracted from the client requirements are stated in detail as follows:

- The user would be able to use the system to determine where they can introduce home delivery for Spanish production by displaying different types of analytic maps and interacting with these maps.

- The user would be able to access the system through a web browser and use the Internet to retrieve the information from the hosted server.

- The user would be able to display different maps for five of California counties: San Bernardino, Los Angeles, Riverside, San Diego, and Orange counties.

- The user would be able to choose functionality in the system where explained in (Table 1.)

- Analytical maps, hard copy maps shows the analysis result and help the user to determine where can introduce the home delivery. 
Table 1. System Functions

\begin{tabular}{|l|l|}
\hline Functions & Description \\
\hline Visualize location & $\begin{array}{l}\text { The user would be able to use a search engine to locate the area } \\
\text { desired. The system should provide different methods of search } \\
\text { including: search by ZIP code, search by area, and search by county. } \\
\text { The user would be able to choose between the layer and information } \\
\text { desired to be displayed from the different analytical maps provided } \\
\text { by the system. Also the user would be able to move between listed } \\
\text { maps and overlay the different maps by using the map tools } \\
\text { provided }\end{array}$ \\
\hline Search location & $\begin{array}{l}\text { The system would allow the user to search for location and display } \\
\text { information related to it on the map (search by ZIP code, search by } \\
\text { area, and search by county). }\end{array}$ \\
\hline
\end{tabular}

\subsubsection{Non-Functional Requirements}

Non-functional requirements for the system include a user-friendly interface that allows users to use the functions easily and helps user navigate between the maps. Several features of the system that made it successful include clearly designed maps with meaningful symbology, centralized map display area, and icons that can easily to be hid and displayed. Table 2 summaries the non-functional requirements.

Table 2. Non- Functional requirements

\begin{tabular}{|l|l|}
\hline Technical & $\underline{\text { Description }}$ \\
\hline platform & $\begin{array}{l}\text { Windows (XP, 7) client side. ESRI ArcGIS desktop and windows } \\
\text { server 2003 in server side. Flash builder for coding and } \\
\text { development. }\end{array}$ \\
Network & $\begin{array}{l}\text { Internet is used to access the server and use the web application. } \\
\text { Internet will be enough for the first year of support and maintenance, } \\
\text { after that the intranet will be used to access the server. }\end{array}$ \\
\hline Operational & $\underline{\text { Description }}$ \\
\hline $\begin{array}{l}\text { Retrieve data } \\
\text { easily and } \\
\text { smoothly }\end{array}$ & $\begin{array}{l}\text { Bandwidth given to retrieve the data from the server easily and } \\
\text { smoothly. After one year support and maintenance the system should } \\
\text { be hosted in the client's server. }\end{array}$ \\
\hline
\end{tabular}




\begin{tabular}{|l|l|}
\hline Technical & Description \\
\hline Database update & $\begin{array}{l}\text { System database will be updated every 10 years with the release of } \\
\text { new census data or with the new release of Business Analyst data } \\
\text { provided by ESRI }\end{array}$ \\
Downtime & $\begin{array}{l}\text { Since the application is information provider and it is not used on } \\
\text { daily basis, downtime is allowed from 1 to 2 days }\end{array}$ \\
\hline
\end{tabular}

\subsection{System Design}

System design must be specified properly to support user performance requirements. Missing one piece of the system will limit performance and will result in higher costs with further development. System design considers user needs, the requirements, the technology to be used, and the overall system architecture.

System architecture design is a process developed to promote successful system operations. This process is built on existing information technology (IT) infrastructure (server side) and provides specific recommendations for hardware and network solutions based on existing and projected user needs. The system architecture contained two main tiers: client tier and server tier. The client would be able to access the application through the Internet and the web server with the ArcGIS server, which would access the database to fetch data (Figure 3-1). The recommended workstation for client side is a GIS standard workstation (Dual Core Intel Xeon processor 5130; $2 \mathrm{GHz}, 4 \mathrm{MB}$ L2, 16MB memory; 80GB hard drive). In the client tier the user would be able to use the workstation to access the web application and retrieve the data through the internet. The sever tier contained the internet server and the ArcGIS server. ArcGIS server contained the GIS data, the GIS data retrieved from the server by the client, and the development workstation. The development workstation contained the ArcGIS desktop application that produced the hardcopy maps and the analyses results. 


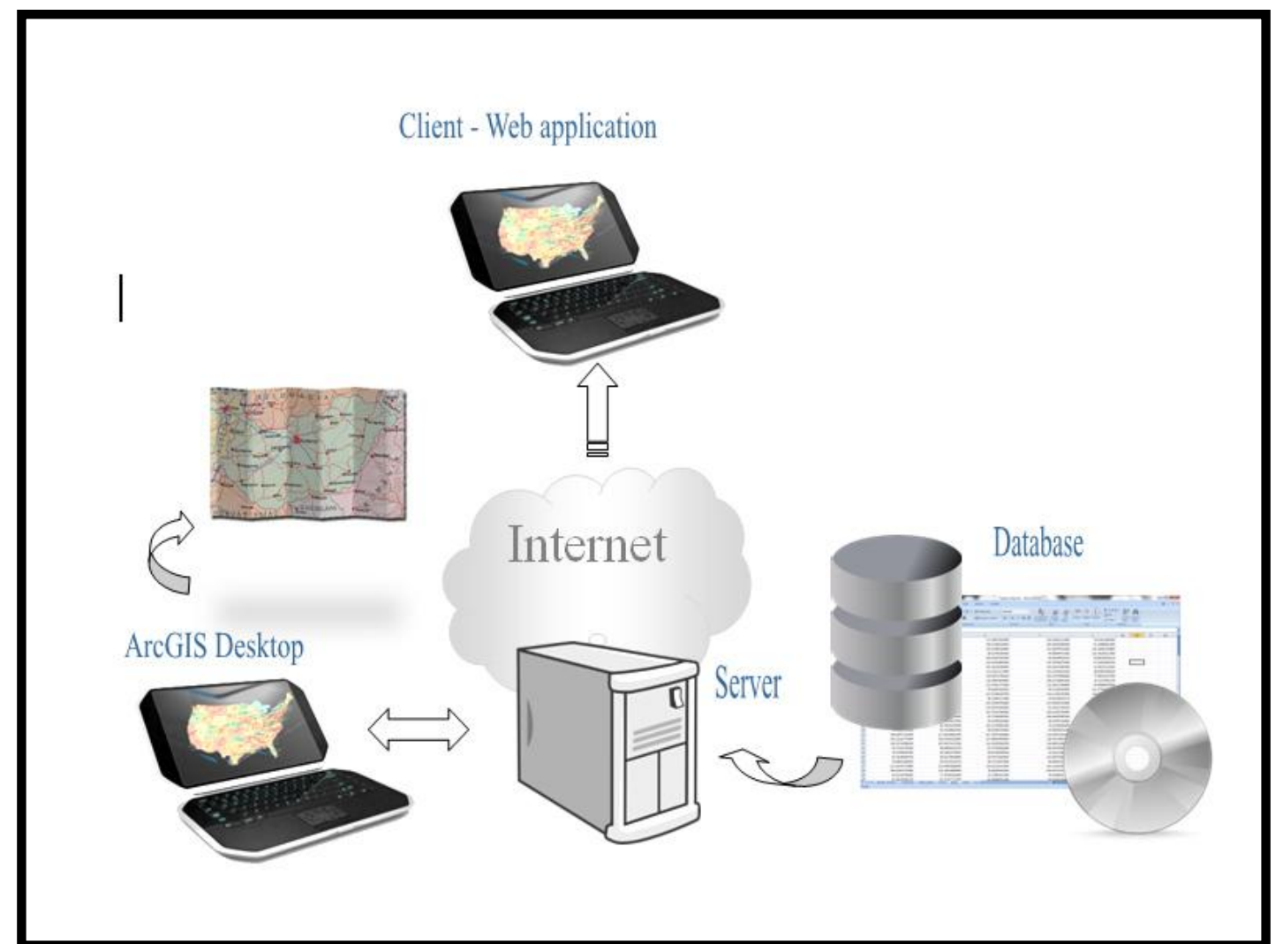

Figure 3-1: System Architecture Diagram

\subsection{Project Plan}

The project plan contained several phases and each phase included different specific tasks. Having a feasible project plan helps maintain the project progress and direction within the required project time frame. However, the project plan was changed and modified during the implementation due to the unexpected technical difficulties or data availability. The project was divided into five main phases along with one self improvement phase; this phase included the ArcGIS training and Flex training needed for development. Project phases were:

- Initiation Phase

- Self Improvement

- Planning Phase

- Executing Phase

- Monitor and Control Phase

- Project Closing Phase

The Initiation phase described the project and specified the business needs. This phase involved creating a preliminary scope statement and project proposal, outlining the main tasks based on the client's requirements and background review. The Planning 
phase discussed all planning processes for different constituent processes and interactions to plan and manage a successful project. In this phase the project plan was created, project scope was defined, work breakdown structure (WBS) was created, tasks were specified, and other activities were defined, like the project communication. The Executing phase was the action phase that executed the plan in parallel with project quality assurance. This phase workflow divided into three main tasks to execute and manage the project plan. The first task was to collect the data and work with it. This task used Shewhart's (1950) 'Plan -Do- Check and Act' too heavily, which caused more time than expected (Figure 3-2).

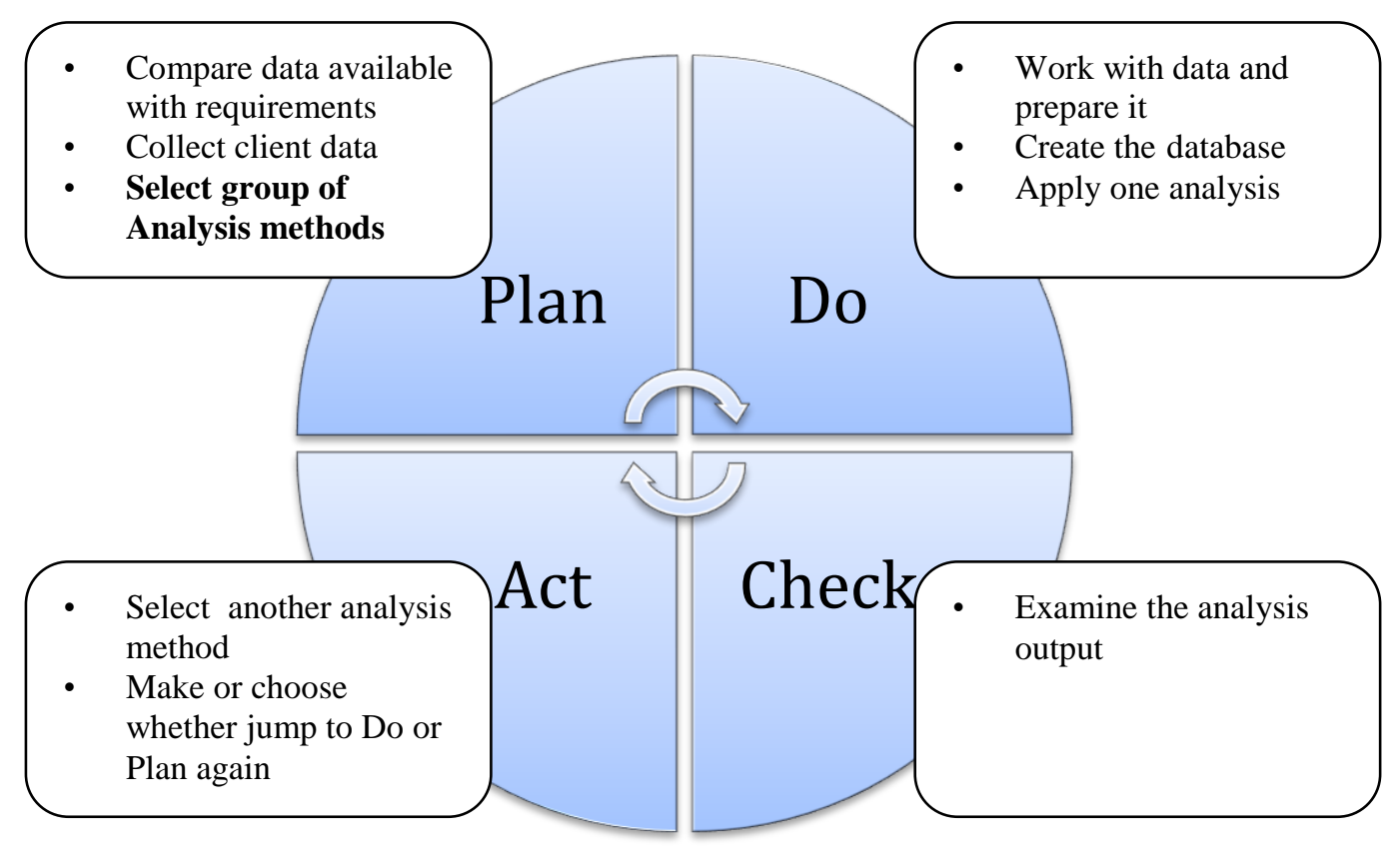

Figure 3-2: Executing Phase Diagram - Collect and Work with Data

The second task in the executing phase was to create maps. This task included creating a map template and applying this template to the data output from the analysis. Developing the web application was the last task in the executing phase where the web application was developed. The web application development was not included in the main client requirement, but was added to allow the user access the demographic maps at the level of block groups. This task was divided into subtasks: design the application, development and programming, test the application, and update to reach the final application. Executing phase deliverables can be summarized as follows:

- Analyze data: GIS data in format, like layers showed the targeted location for the client's current and potential market and showed different analysis results. This is considered the core of the project, and the most important deliverable, and with this data the project has met the analysis required from the client.

- Map templates: the hardcopy maps were provided in this phase as template. This is one of the outputs provided by the project as the final product will show the analyzed data and the client analysis output in the form of map reports. 
- Web application: this is the final product of the project. Web application allows the client to interact with analytical maps. The web application was another presentation for the analytical maps and gives the client the option of viewing the maps as softcopy. This web application was customized to have the functionality of the GIS application, like zoom in or zoom out. The idea of the web application is that the client can access it in different places for presenting purposes.

The Monitoring and Controlling phase contained the tasks of monitoring and controlling the project work, making sure that scope statement was met, controlling the project schedule, and monitoring project risks. The Closing phase was the end of the project after the final deliverables of the project were submitted to the client. The project was completed by gaining the approval of the client.

\subsection{Summary}

Although the project faced some difficulties during it implementation, such as lack of data and delays in receiving them from client, the project fulfilled the main objective. Focus on achieving return on analysis maps and taking time in planning different aspects of the project were the keys to the success of this project. In addition, making sure the client's objective of locating the Hispanic customer and identifying the target locations was met. 


\section{Chapter 4 - Database Design}

This chapter explains the conceptual model for this project and the entities needed to be included in the database. The logical model was also defined to contain all required datasets in form of the Esri geodatabase. After specifying the data needed and collecting them from their sources, the database was created, and the data were loaded into the geodatabase.

\subsection{Conceptual Data Model}

The conceptual model is where entities involved in the project are defined, relations between the entities are specified, and attributes needed for those entities are declared. This design model gives a clear idea about required data for the analysis. It will identify the features and relationships.

Unified Modeling Language (UML) diagrams were created in Visio to show the conceptual diagram for this project, which contains two main entities: La Prensa distribution stores and block groups (Figure 4-1). Block groups were selected as one of the main entities because the analysis result is requested by the client to display at the block groups level. Some block groups contained one distribution store and other contained more than one stores. Also there was some block groups that did not contain any distribution store. There were also different entities involved in the project to present the base map. Those entities represented as: counties boundaries, ZIP codes, block groups.

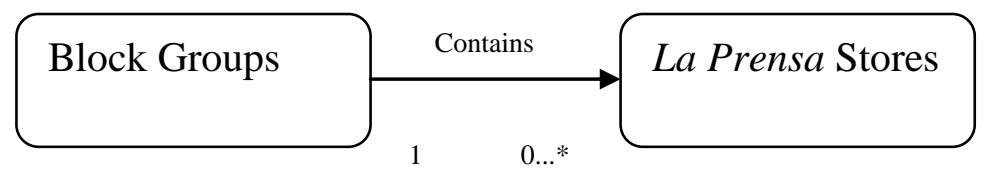

\section{Figure 4-1: Conceptual Diagram}

\subsection{Logical Data Model}

The logical model was derived from the conceptual model. In this model, scheme of identifiers, or keys, for the unique identification of each entity is declared and a list of attributes is defined. The geodatabase used for this project is simple and is composed of two feature datasets: LaPrensa_stores and BaseMap (Figure 4-2). The LaPrensa_Store feature dataset only contains a point feature class representing La Prensa stores. The attributes related to this feature class was derived from the original data from the client, which includes address of the stores, the name of the stores, and the rate of La Prensa distribution in each store (DRAW). The base map was needed to draw the study area and represent the analysis output. The government's boundaries were used as the base map such as counties, ZIP codes, and block groups. Attributes related to each base map feature class were derived directly from original feature classes, and these attributes were selected by the recommendation from the literature review and by the request from the 
client. Most of attributes pertains to the socio-economic characteristics of each block group, including total population, Hispanic population, total households income, education, adult male population, adult female population, block group area, and block group name.

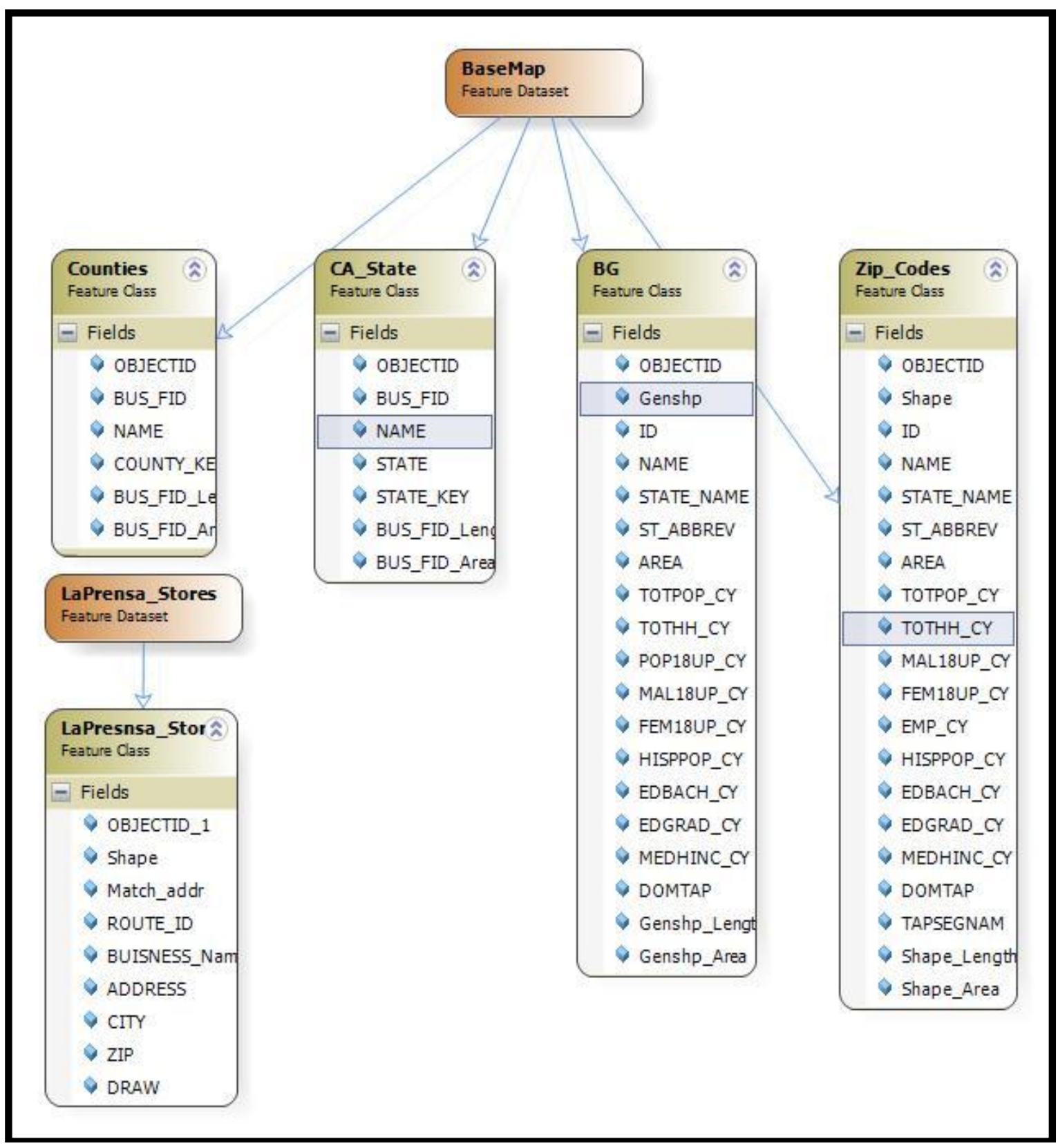

\section{4-2 Logical Diagram - Feature Class Attributes}




\subsection{Data Sources}

There were two different data sources for this project: excel sheet data from the client containing location of retails stores with the number of distribution, and the Esri Business Analyst data for the demographic data. The base map data came from two sources: Business Analyst and ArcGIS online data map service.

\subsubsection{Client Data}

The client provided data as an excel sheet which contains the Spanish newspaper retail stores and news racks where the newspaper is distributed. The retail store data fields are explained in Table 3. This data provided addresses for each store or news racks. Although some data had accurate addresses, some did not. Comparing the relationship between the retail store data and the block groups, some block groups had one stores and other block groups had many stores. The client was using the ZIP code as an administration boundary to check their distribution level. These stores or news rack data were selected according to guess work or previous knowledge of Hispanic concentration, thus there were no specific criteria to select the locations.

\section{Table 3. Client Excel Data}

\begin{tabular}{|l|l|}
\hline Field & Description \\
\hline ROUTE ID & $\begin{array}{l}\text { Alphanumeric. Route ID used by the client shows the addresses } \\
\text { belonging to which route of distribution. }\end{array}$ \\
\hline BUINESS NAME & $\begin{array}{l}\text { Shows the store name or business name that the distribution happens } \\
\text { in or nearby where the newspaper is distributed. }\end{array}$ \\
\hline Address & Address of the location of the distribution (actual or nearby) \\
\hline City & City name where the store is located. \\
\hline ZIP & ZIP codes where the store is located. \\
\hline DRAW & $\begin{array}{l}\text { The DRAW indicates only the number of newspapers placed on the } \\
\text { rack. The lower the number means lower Hispanic traffic picking up } \\
\text { newspapers. The higher number means that more Hispanic bought } \\
\text { newspapers, thus signifying higher traffic volumes. }\end{array}$ \\
\hline
\end{tabular}

\subsubsection{ESRI Business Analyst Data}

Demographic data were the key to this project analysis. The Esri Business Analyst suite is composed of Web-based, desktop, and server applications that enable businesses to access a wealth of data. The data used for this project was Business Analyst desktop data. Block group data were customized for this project's purpose. In addition to the block group dataset, this project included Esri's Market Potential data, which provides information about the newspaper reader in a table. It measures the likely demand for a product or service in an area. The data include an expected number of consumers and a Market Potential Index (MPI) for each product or service. An MPI compares the demand for a specific product or service in an area with the national demand for that product or 
service. The MPI values at the U.S. level are 100, representing overall demand. A value of more than 100 represents higher demand, and a value of less than 100 represents lower demand. For example, an index of 120 implies that demand in the area is likely to be 20 percent higher than the U.S. average; an index of 85 implies a demand that is 15 percent lower (ESRI, 2009b). MPI values are linked with Tapestry Segmentation values in the block group attributes table. Tapestry Segmentation classifies all U.S. residential neighborhoods into 65 segments based on socioeconomic and demographic characteristics The Tapestry Segmentation allows to profile consumers. The 65 segments divided into summary groups for a broader view of U.S. neighborhoods by the life Mode: 12 summary groups based on lifestyle, and urbanization: 11 summary groups based on geographic and physical features along with income. MPI data were mainly used during the analysis process and was not loaded into the database.

\subsection{Data Scrubbing and Loading}

Data from the client were modified and geocoded to get the accurate location of the stores. The address locator, US _street_addresses, was used to geocoded the store addresses against the Tele Atlas Street Address Range database (US Nationwide streets). The output feature class, La Prensa Retails stores, contains more than 2000 locations. However, a majority of the stores do not have the information on the La Prensa distribution. Therefore, these stores were removed and only 618 stores were included for the analysis. The final feature class, LaPrensa_stores, has the same attributes listed in Table 3 with one field added to contain the matching address from the geocoding process. The base map data were imported to project the database by selecting required data and attributes.

\subsection{Summary}

The conceptual data model explains needed entities and the main entities used for analysis. After defining the conceptual model, it was determined that the logical model needed to consist of the geodatabase. The logical model explained the datasets, which were created and loaded into the geodatabase. Because the client had provided the data in the form of an excel sheet, only the geocoding process was needed to make sure that the data were exported into the geodatabase points form. 


\section{Chapter 5 - Implementation}

The implementation of this project was composed of two major tasks: analyzing the relationship between La Prensa distribution and neighborhoods, and building the web application. To determine the impact of neighborhood characteristics on La Prensa distribution, four types of analyses were conducted: cluster analysis, trade area analysis, regression analysis, and Find Similar analysis. The results suggested the target locations for home delivery of La Prensa. The web application was developed using Flex to customize main functions including: search by ZIP code, search by county, identify block groups, and maps tools. Hard copy maps of analysis results were also delivered to the client.

\subsection{Analyzing the Relationship between Neighborhood Characteristics and La Prensa Distribution}

Analyzing the relationship between neighborhood characteristics and La Prensa distribution started with finding store clusters, as the distribution stores selected by the client were already clustered. Based on the store clusters, a trade area analysis was carried out to examine the impact of neighborhood characteristics on the distribution of La Prensa newspaper. Finally, the target areas were recommended by finding the neighborhoods similar to the trade areas that already had high distribution. Figure 5-1 summarizes the analytical flow.
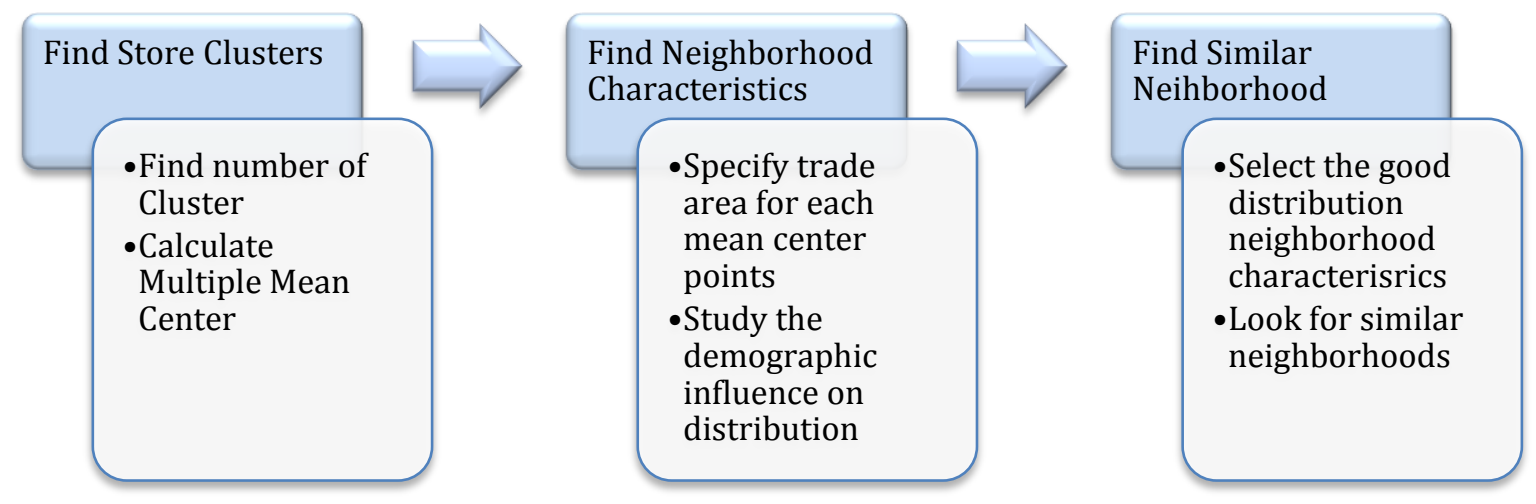

Figure 5-1: Analyzing Relationship Between Neighborhood Characteristics and $\mathbf{L a}$ Prensa Distribution Workflow

\subsubsection{Finding Trade Area of Store Clusters}

In some cases the stores were very close to each other; some were even found in the same shopping mall. This suggests that it is difficult to link each individual store with its own individual neighborhood. Therefore, cluster analysis was conducted to identify store clusters that existed in the current newspaper distributors (the stores where the newspaper is distributed for free). The Multiple Mean Center Tool in Business Analyst was used to 
solve this problem. However, this tool requires the number of clusters to be one input parameter; since it uses the k-means clustering method. To figure out the appropriate number of clusters, an algorithm called Find Multiple Mean Center was implemented using a Python script (see Appendix B for details). The Find Multiple Mean Center accepts two inputs: two and a half mile buffer around each store as a polygon feature class, and La Prensa stores feature class. Buffers around each store were created using the Buffer tool from the analysis toolbox in ArcMap. The distance used to create buffer zones around stores was two and a half miles ( 2.5 miles). This distance was determined according to the assumption that stores located within a five minute driving distance belong to the same cluster. Given that the average driving speed is $30 \mathrm{mph}$ in an urban area, the five minute driving distance is about 2.5 miles. Using the stores and their buffer zones, the Find Multiple Mean Center iteratively created a hierarchy of mean centers for different clusters of stores. Initially, stores within each buffer were selected, and then the mean center for each group of selected stores was found. The sum of the distribution of the selected group of stores was calculated and added to the mean center point. After six iterations, no two mean centers remained separated by less than 2.5 miles. A total of 32 clusters were obtained and this number was used as an input to the k-means clustering tool in Business Analyst (BA).

The k-means approach finds geographic concentrations in a set of points and determines their center points. After identifying a cluster partition, the process continues iteratively until all points are associated with the closest mean center. To account for the distribution volume of each store, the weighted mean center was used in this method and 32 store clusters were identified. The total number of distributions of La Prensa for each cluster was one of the output attributes, which was used for the regression analysis. Using the BA's k-means clustering tool and the customized Find Multiple Mean Center tool, two sets of clusters were obtained. To a great extent, the two sets of clusters were similar, which will be further discussed in Chapter 6 .

Trade area analysis was performed after the cluster analysis to find the customers within a five minute driving distance of each distribution cluster. In this analysis, Network Analyst was selected to calculate driving time on the street network. After the trade areas were found, the overlay tool in BA was used to aggregate the demographic data at the block group level for each trade area. As explained in Chapter 2, the areabased aggregation method was chosen because it allows for the aggregation of the most desired demographic variables. .

The variables aggregated from overlay analysis included:

- 2009 Male Population 18+

- 2009 Female Population 18+

- 2009 Total Hispanic Population

- 2009 Total household

- 2009 Unemployed Population 16+

- 2009 Education 25+ Bach Deg

- 2009 Education 25+ Grad Deg

- 2009 Medium household Income

In addition to the demographic variables, Market Potential Index (MPI) data were also considered for the regression analysis. MPI data provide information about customers' reading behaviors within the trade area. However, MPI was not aggregated in 
the overlay process. These data were available in a table. Columns represented index numbers that were a reference for the Tapestry segment. Rows contained the index values for different goods, services, attitudes, and activities. Three main values were selected from the reading behavior: Light Newspaper Reader, Medium Newspaper Reader, and Heavy Newspaper Reader.

The MPI data were added to the original trade area attribute table using the Join Field toolbox available in ArcMap. Join Field was the dominant Tapestry segment (DOMTAP: Dominant Tapestry Code) in the trade area attribute table and Indexes in the MPI data. MPI data were first exported and opened in Excel; then spatial paste and transpose functions were used to get the indexes into rows. The result was joined to the trade area attribute table (Appendix A).

\subsubsection{Examining Neighborhood Demographic Characteristics}

One previous study (George \& Waldfogel, 2003) showed that blacks and whites are more likely to buy daily newspapers in markets with respectively larger black and white populations. Similar results hold for Hispanics and non-Hispanics. In this analysis, the interest was in whether the La Prensa distribution significantly depended on the Hispanic population, and whether there were other factors influencing the distribution. A regression analysis model was built to examine the variables that may affect the distribution of the newspaper. PASW Statistics 18 software was used to run the regression analysis. Table 4 summarizes both dependent variables and independent variables that were taken into account. First, correlation analysis was applied to each pair of variables to test how strongly they were associated. The independent variables that were not significantly correlated were chosen to be included into the regression model. The model coefficients were estimated using the least square method.

Table 4. Variables Involved in Exploratory Stage in Regression

\begin{tabular}{|l|l|}
\hline Response variable & Description \\
\hline DRAW & Newspaper distribution aggregated at each cluster \\
\hline$\underline{\text { Explanatory variable }}$ & $\underline{\text { Description }}$ \\
\hline Number of stores & The number of stores represented by each cluster. \\
\hline
\end{tabular}




\begin{tabular}{|c|c|}
\hline 2009 Male Population 18+ & Male population age 18 and above \\
\hline 2009 Total Hispanic Population & Hispanic Origin total population \\
\hline \multicolumn{2}{|l|}{2009 Total households } \\
\hline $\begin{array}{l}2009 \text { Unemployed Population } \\
16+\end{array}$ & $\begin{array}{l}\text { Unemployed population whose age is } 16 \text { years } \\
\text { and above }\end{array}$ \\
\hline 2009 Education 25+ Bach Deg & $\begin{array}{l}\text { Population age } 25 \text { and above by Educational } \\
\text { Attainment: Bachelor's Degree }\end{array}$ \\
\hline \multicolumn{2}{|l|}{2009 Medium household Income } \\
\hline 2009 Hispanic Percentage & Percentage of Hispanic origin population \\
\hline 2009 Male $18+$ percentage & Percentage of male population age 18 and above \\
\hline $\begin{array}{l}2009 \text { Unemployed Population } \\
\text { 16+ Percentage }\end{array}$ & $\begin{array}{l}\text { Percentage of Unemployed population age } 16 \\
\text { and above }\end{array}$ \\
\hline Heavy newspaper reader & $\begin{array}{l}\text { Market potential Indexes value for Heavy } \\
\text { newspaper reading behavior }\end{array}$ \\
\hline
\end{tabular}

Once the model was estimated, it was evaluated based on the $\mathrm{F}$ test result and $\mathrm{R}^{2}$, as well as the t test results for each individual independent variable. The final model includes only the significant variables and will be discussed in detail in Chapter 6.

\subsubsection{Find Similar Neighborhoods}

Business Analyst provides Find Similar analysis based on scoring locations against a known and well performing distribution location. It is based on the idea that the characteristics of a good distribution location can be found elsewhere. This tool was used to find the areas that have similar demographic characteristics to that of high distribution trade areas. Therefore, the highest distribution trade area was selected to be the master site, against which the similar block groups were to be found. The demographic characteristics for comparison were indicated by the previous regression analysis results. There were two approaches provided by this tool and the Conventional Find Similar method was used. The Conventional Find Similar method ranks the block groups by comparing the values of demographic variables with $+/$ - percentage of changes from the value in the master site.

\subsection{Building Web Application}

Creating the web application required preparing documents to display the analysis results and different maps. This map document contained the layers to be shown in the web 
application. The map document contains La Prensa stores and the base map, with the analysis results shown for the block groups. While preparing the document, the natural breaks was used to classify the demographic characteristics for each layer technique. After preparing the map document, hardcopy maps were printed and ArcGIS map services were created.

The web application was developed using ArcGIS map services and the Flex framework. It was designed and built using Adobe Flash builder 4.0, The Adobe Flash plug-in will be automatically installed on the client's side when the application is first run. ArcGIS map services are displayed in the web application. This web application was built to allow the client to interact with different demographic maps and the analysis results. ArcGIS resource center sample codes were used as a reference to implement the functions available in the application. To build the web application, interface design specification was set (Figure 5-2). Using C\# programming language and Extensible Markup Language (xml) in the Flash builder, and with the help of the samples codes, the web application was built with the functions shown below:

1. Search: two types of searches are provided. Search by ZIP code and search by county. A window will be displayed when the user clicks on search function and he/she can choose desired search type.

2. Explore: different tools were created to allow the user to explore the different maps, including pan, zoom in, zoom out, full extent, next extent, previous extent, and the ability to switch between different layers. A transparent tool was included to control the maps transparency, and an Identify tool to retrieve demographic information.

3. Legend: a legend is also provided to show the layers legend.

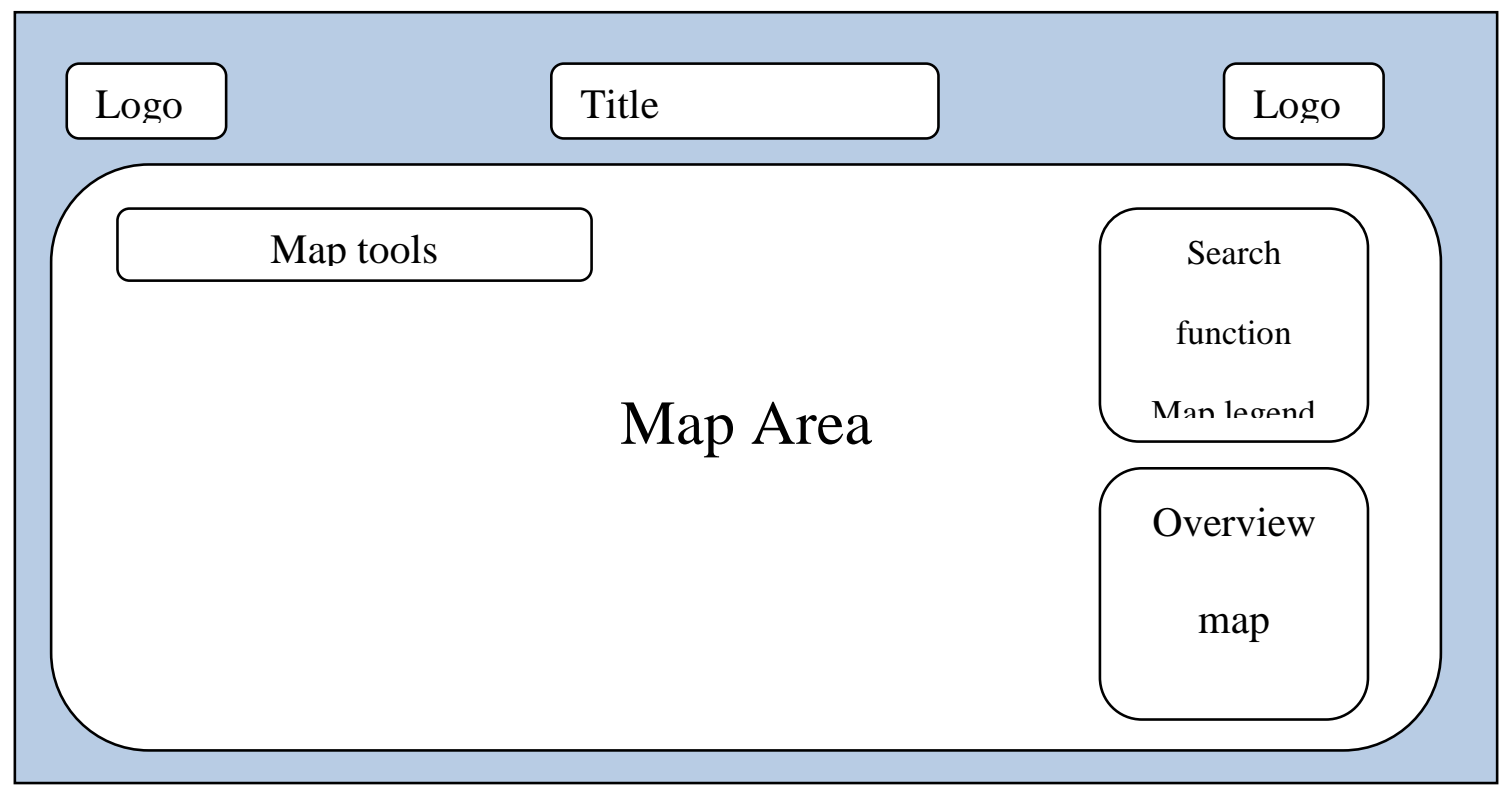

Figure 5-2: Web Application Interface Design 


\subsection{Summary}

Using the weighted mean center to find the store clusters helped in analyzing the relationship between the neighborhoods and La Prensa stores. Clustering was implemented using the find multiple mean center iteration tool and Business Analyst mean center. After identifying clusters of La Prensa stores, demographic characteristics were studied using different analyses: trade area analysis, regression analysis, and find similar analysis. These analyses used the cluster points and studied the five minute trade area for each point. Analysis output was presented in a web application with flex and hard copy maps. 


\section{Chapter 6 - Results and Analysis}

This chapter focuses on the analysis results. Using the aggregated demographic variables for the trade areas, the regression model suggested that Hispanic populations significantly influence the La Prensa distribution, which met the client's expectation. Based on this variable, the Find Similar analysis compared the Hispanic population of all block groups to that of the trade area that has the highest distribution. Similar block groups were found and communicated to the client through a web interface. The web application allows the client to interact with different demographic maps and retrieve relevant information.

\subsection{Relationship Between Neighborhood Characteristics and La Prensa Distribution}

\subsubsection{Trade Areas of Store Clusters}

Thirty-two store clusters were produced after implementing the Find Multiple Mean Center iterations. This result was used as the input for the Business Analyst K-means Multiple Mean Center tool (Figure 6-1). There are slight differences between the two sets of clusters due to the different methods used. The major difference was in the areas that have fewer distribution stores. Using the multiple mean center iterations, a single store will be taken as a cluster by itself when it is apart from other stores for more than 2.5 miles. However, this criterion does not apply to the k-means clustering tool in BA. Therefore, in the areas that have a lower density of stores, a cluster can be produced with a group of stores that are distant from each other. Put differently, the cluster location (or the mean center location) is not necessarily close to the stores when the K-means clustering method is applied. The following analyses were conducted using both sets of clusters and the results are compared (Figures 6-1 and 6-2). 


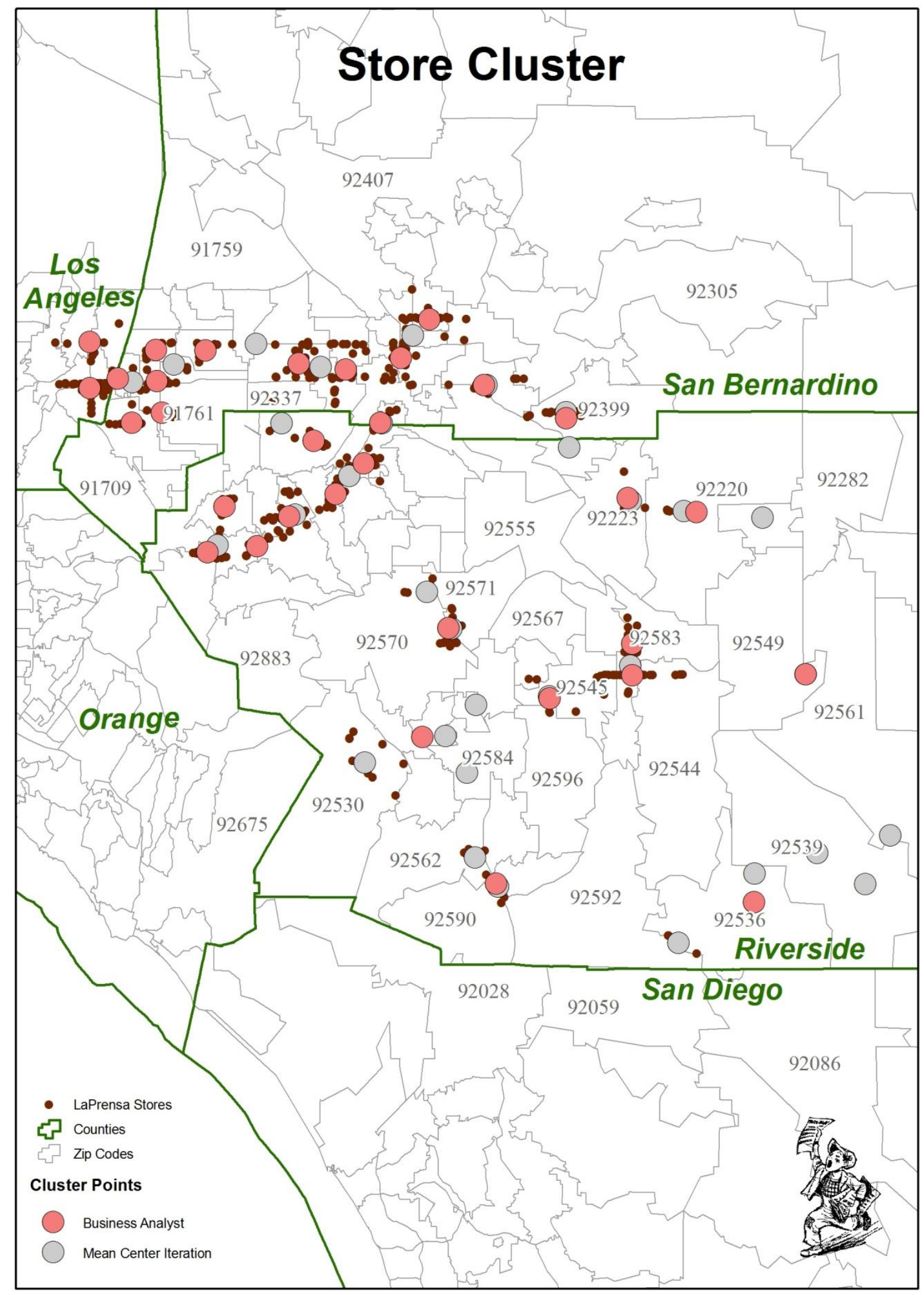

Figure 6-1 La Prensa Store Clusters by Business Analyst and Find Mean Center Iterations 
To find the relationship between the neighborhood characteristics and the newspaper distribution, it was necessary to first define the neighborhood. In this study, a five-minute driving trade area was chosen as the neighborhood for each cluster, based on the assumption that people are willing to travel five minutes to pick up the newspaper. Figure 6-2 shows the trade areas created for the BA's clusters. It can be seen that not all stores fall in the trade areas (highlighted by the red ellipses on the map). This is because some cluster locations are relatively far away from the comprising stores in some areas. 


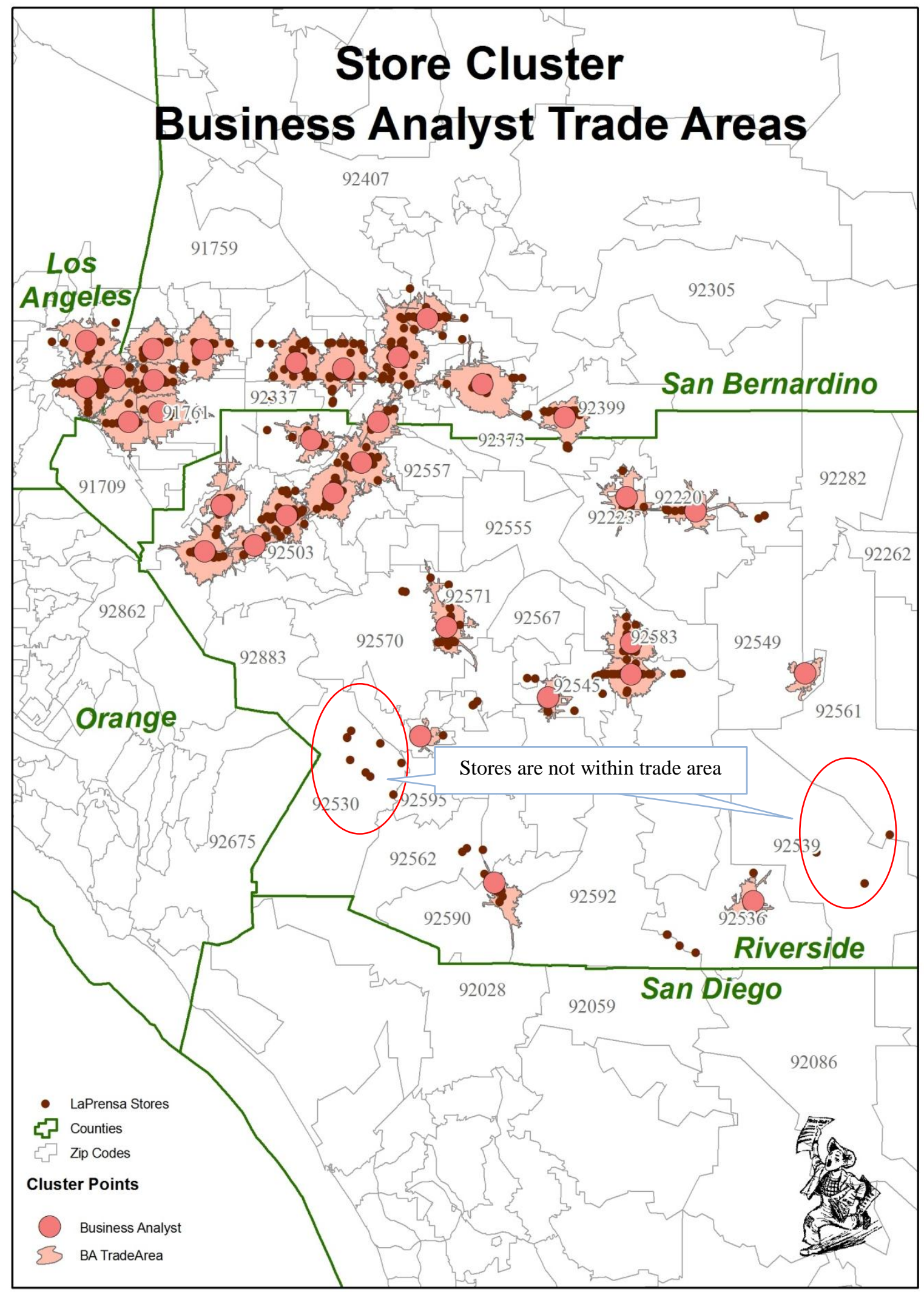

Figure 6-2: Trade Areas Based on Business Analyst Mean Center 
Compared to the trade area coverage of BA clusters, the trade area coverage of the clusters calculated by the multiple mean center iterations was improved (Figure 6-3). Once these two sets of neighborhoods were defined, the related demographic variables were aggregated to the trade area from the block group level. 


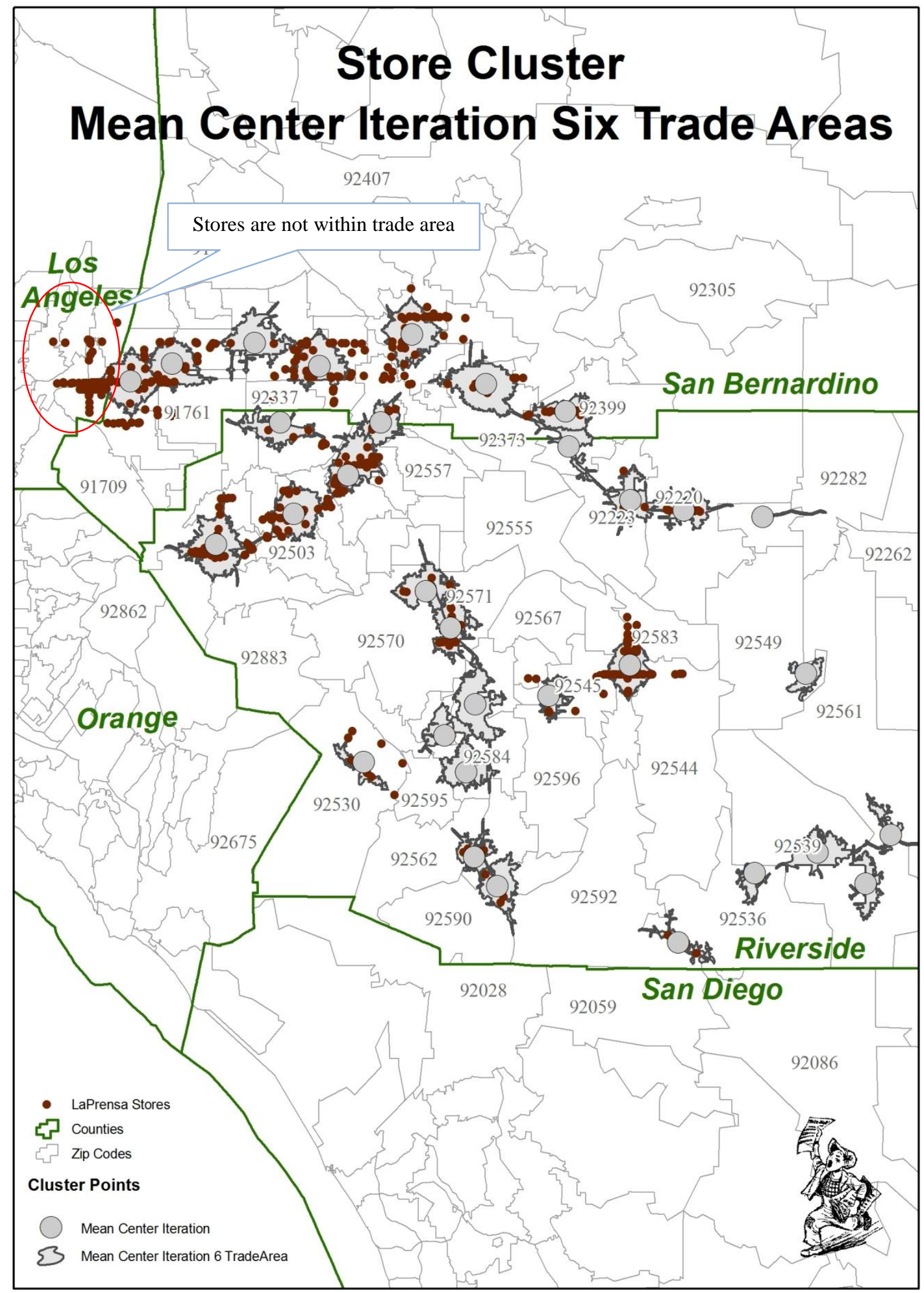

Figure 6-3: Trade Areas Based on Find Mean Center Iterations 


\subsubsection{Neighborhood Demographic Characteristics}

The demographic characteristics were calculated for both sets of trade areas, and the results were very similar. For example, the percentage of the population that is Hispanic is between $12.6 \%$ and $79.8 \%$ for the BA's trade areas, with a mean of $49.6 \%$ and standard deviation of $16.8 \%$. For the trade areas created by the custom algorithm, the percentage of the population that is Hispanic is between $12.6 \%$ and $69.5 \%$, with a mean of $40.7 \%$ and standard deviation of $18.2 \%$. Further, the Tapestry segments of 38 and 21 dominate both sets of trade areas. Tapestry Segment 38 is called Industrious Urban Fringe where $60 \%$ of the residents in this segment are Hispanic. The second dominant Tapestry Segment 21 is called Urban Villages where 62\% of the residents in this segment are Hispanic.

The aggregated demographic values were then used as independent variables for the regression model. The dependent variable was the total number of distributions for each cluster. After multiple trials, the final model included two significant variables: the percentage of population who are Hispanic, and the number of stores associated with the clusters. The total Hispanic population and the Hispanic percentage variables were both significant in the model. However, since they were highly correlated, one of them needed to be dropped. Because the variable that is left in the model will be used to find the similar block groups, the Hispanic percentage is appropriate as it is a normalized variable and can be used for the analysis of different geographical scales. Table 5 summarizes the regression results, and analysis with both sets of trade areas yielded a similar result. With these two variables, the R-square statistic reaches $88 \%$, indicating very good model fitness. First, the number of stores associated with each cluster significantly affects the newspaper distribution. This is reasonable as the distribution at each cluster is the sum of the distribution of associated stores. Therefore, a cluster that is composed of 15 stores is likely to have more distribution than a cluster of two stores. Second, the Hispanic population has a positive impact on the newspaper distribution, which meets the client's expectation as the newspaper is published in Spanish. Further, the Hispanic population should be taken as a compound factor to interpret the result, as a Hispanic culture indicates a certain type of lifestyle, reading preference, and a certain pattern of other behaviors, such as shopping. Although the other demographic variables considered (see Table 4 in Chapter 5) were not significant, it does not mean that these variables are irrelevant to the newspaper distribution. To examine this, individual data (customer information) is required. 
Table 5. Linear Regression Model Result

\section{Business Analyst Mean Center Data}

\begin{tabular}{|c|c|c|c|}
\hline$R=0.932$ & & $F=96.36$ & \\
\hline Adjust R-square $=0.860$ & & Sig. $=.000$ & \\
\hline Dependent : DRAW, La Prensa distrib & ion & & \\
\hline Independent variable & Coefficient & $\underline{t}$ Test & Sig. \\
\hline Constant & -288.416 & -2.407 & 0.023 \\
\hline 2009 Hispanic Population Percentage & 603.009 & 2.431 & 0.021 \\
\hline Stores Count & 42.921 & 11.497 & 0.000 \\
\hline
\end{tabular}

\section{Mean Center Iteration Data}

$R=0.946$

$F=124.198$

Adjust R-square $=0.888$

Sig. $=.000$

Dependent : DRAW, La Prensa distribution

\begin{tabular}{lccc} 
Independent variable & Coefficient & t Test & Sig. \\
\hline Constant & -158.972 & -1.713 & 0.097 \\
\hline 2009 Hispanic Population Percentage & 447.504 & 1.873 & 0.071 \\
\hline Stores Count & 36.927 & 12.593 & 0.000 \\
\hline
\end{tabular}

\subsubsection{Recommendation for target neighborhoods}

Since the regression analysis suggests that the percentage of the population who is Hispanic is the only significant demographic variable, the find similar analysis used this variable as the target variable to find the block groups similar to the master site. The trade area with the highest distribution was chosen to be the master site, and the percentage of the population that is Hispanic for this trade area is $79.8 \%$. Considering the standard deviation of the variable distribution among the trade areas, $20 \%$ was used to create a range for the comparison. Therefore, the Find Similar analysis looked for the census block groups that have a Hispanic percentage ranging between $65.8 \%$ and $98.7 \%$. The results are shown in Figures 6-4, 6-5, and 6-6 for Riverside, Los Angeles, and San Bernardino counties, respectively. These selected areas were recommended to the client for introducing home delivery of La Prensa. Appendices C, D, and E summarize the sample of recommended block groups. 


\section{Riverside, California Targeted Census Block Groups}

One hundred and thirty eight (138) census block groups out of over eight hundred are recommended to be targeted location for La Prensa newspaper based on different analyses applied using Esri census block groups 2009 and La Prensa stores locations.

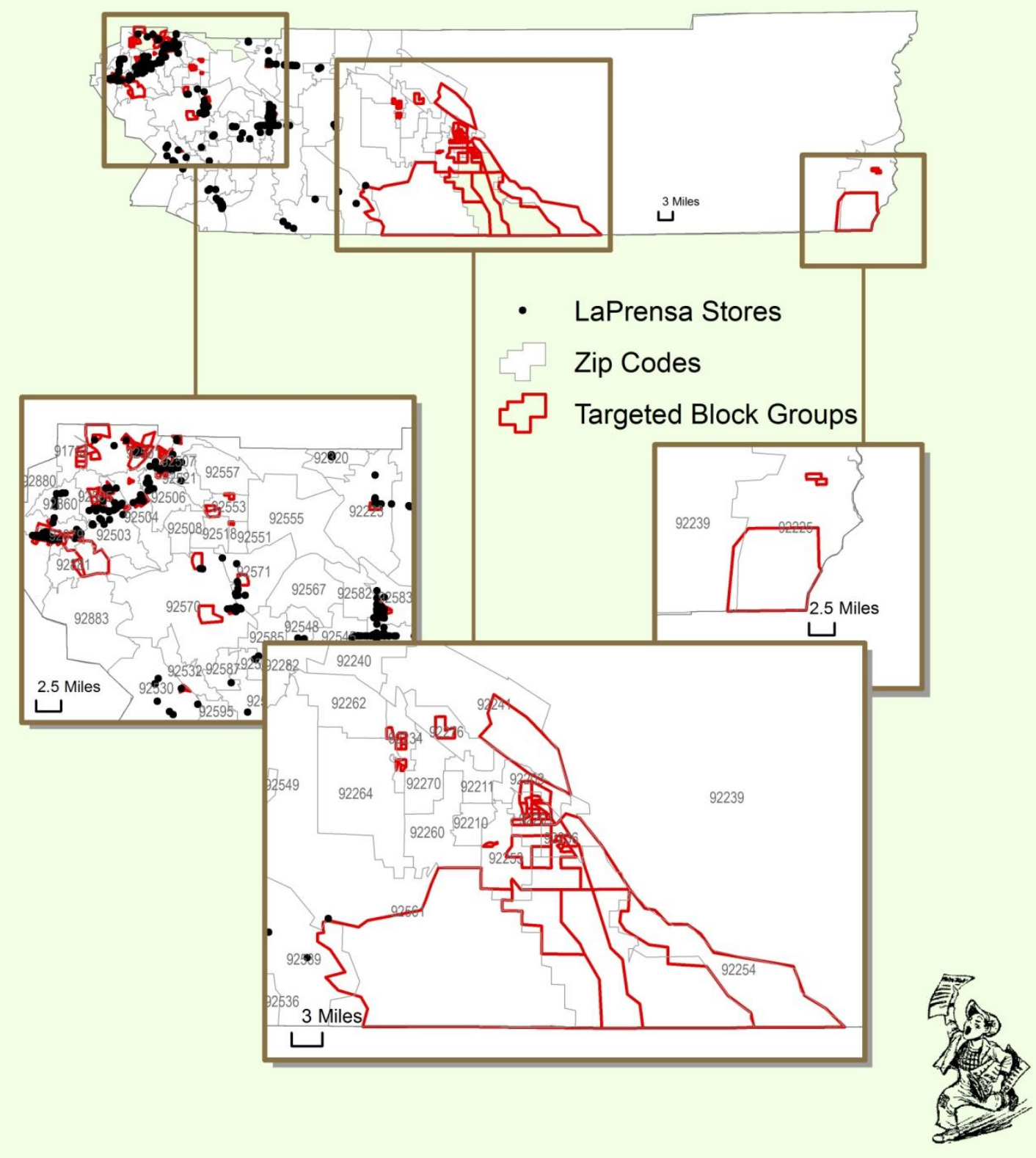

Figure 6-4: Targeted Areas for La Prensa Distribution, Riverside County 


\section{Los Angeles, California Targeted Census Block Groups}

Two Thousand census block groups out of over six thousand are recommended to be targeted locations for La Prensa newspaper based on different analyses applied using Esri census block

groups 2009 and La Prensa store locations.

- LaPrensa Stores Zip Codes

5 Targeted Block Groups
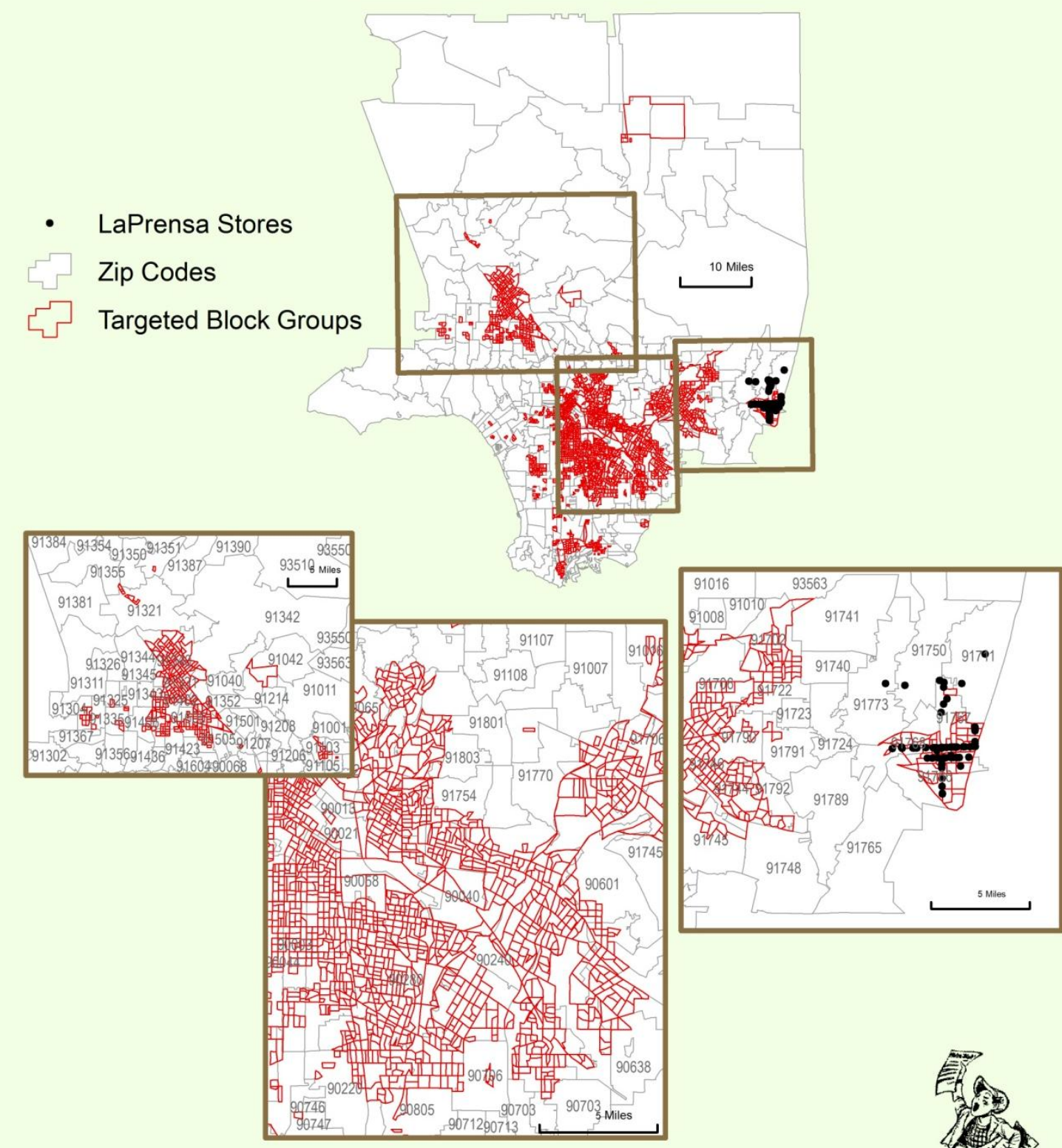

Figure 6-5: Targeted Areas for La Prensa Distribution, Los Angeles County 


\section{San Bernardino, California Targeted Census Block Groups}

Two hundred and fifty six (256) census block groups out of over one thousand are recommended to be targeted locations for La Prensa newspaper based on different analyses applied using Esri census block groups 2009 and La Prensa store locations.

- LaPrensa Stores Zip Codes

T5 Targeted Block Groups
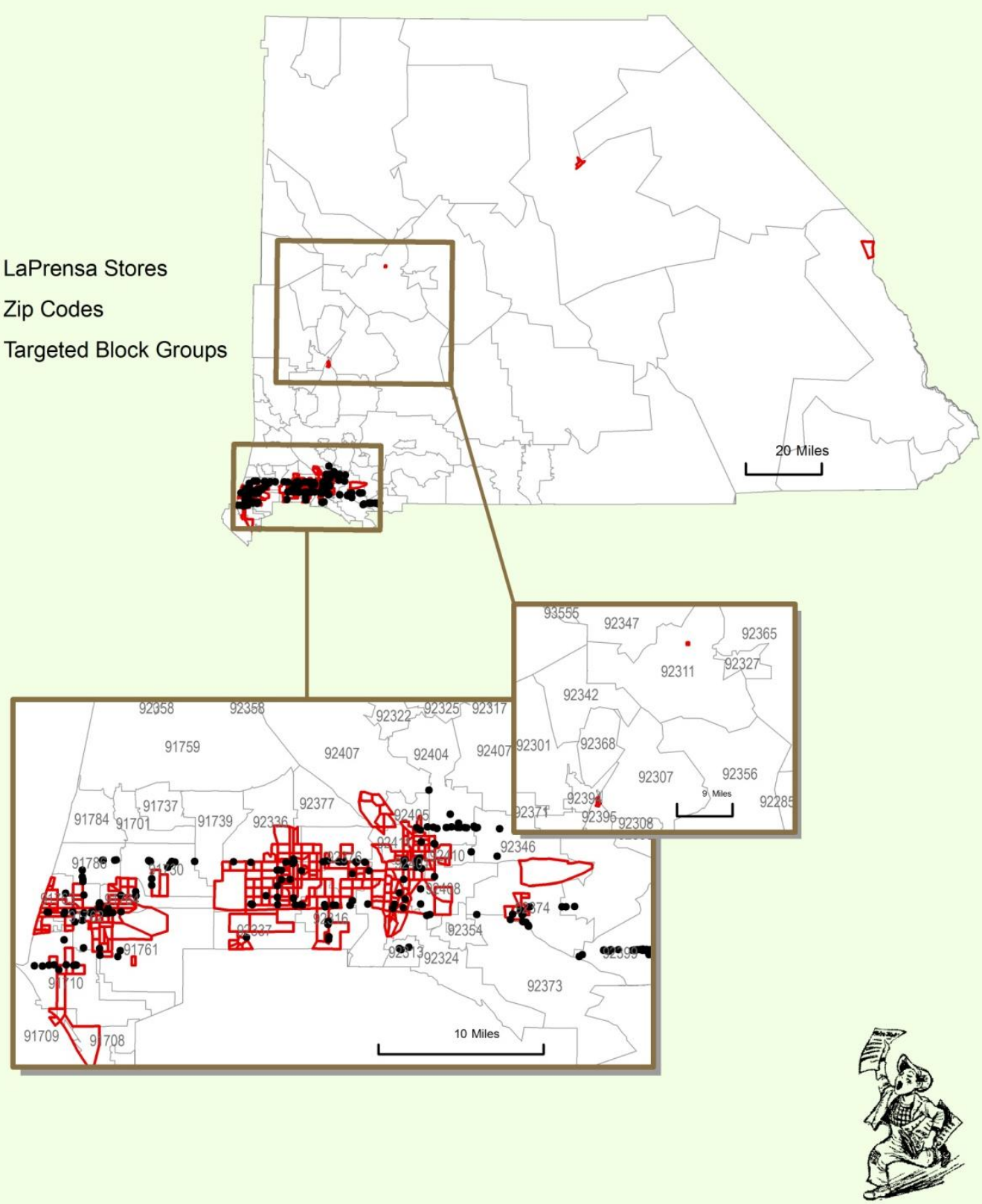

Figure 6-6: Targeted Areas for La Prensa Distribution, San Bernardino County 
Besides the hard copies of the analysis results, these maps and other demographic maps were included in the web application for the client to view, explore, and analyze.

\subsection{Web Application Interface}

The final web application allows the user to display the different results using the functions discussed in Chapter 5. The user can select the function that he would like to use from the function toolbar by clicking on it. When the user clicks on the function a popup window will be displayed (Figure 6-7).

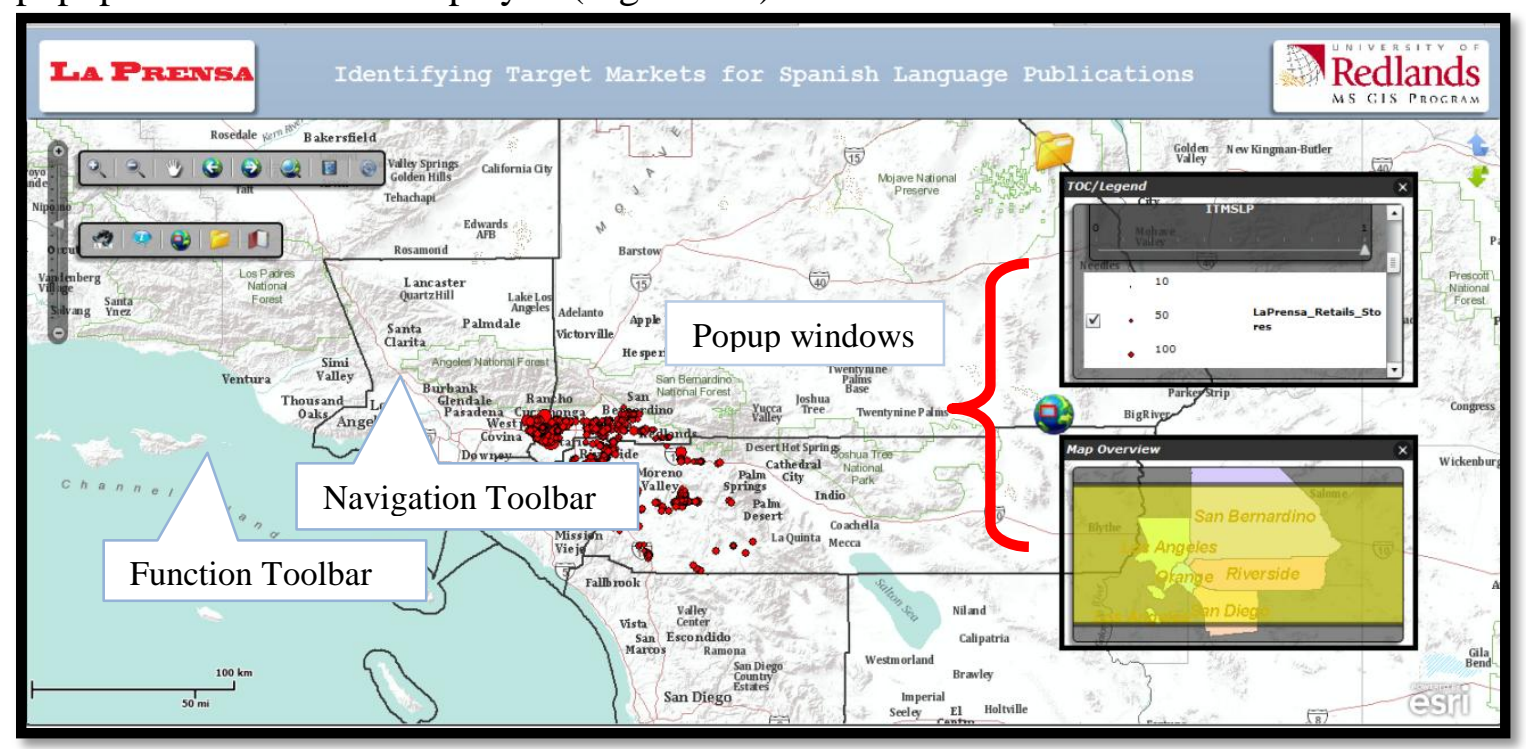

Figure 6-7: ITMSLP Web Application

For example, the user can switch between the different maps to view either the recommended block groups or different demographic maps, including the Hispanic population distribution, the Hispanic percentage distribution, adult male population distribution, adult female population distribution, heavy newspaper reader distribution, and medium household income distribution, each with the legend (Figure 6-8). 

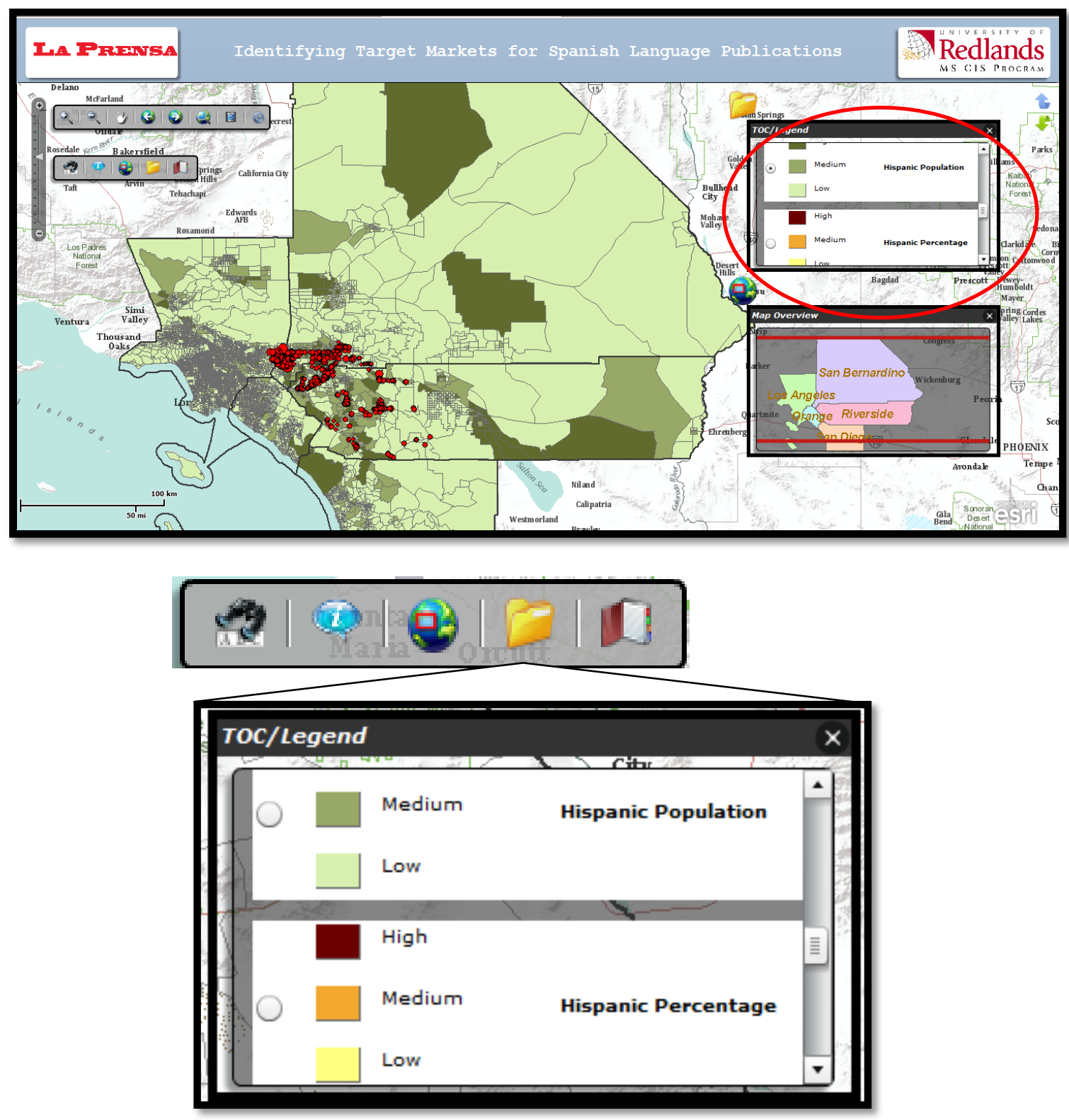

Figure 6-8: Table of Contents Tool and Legend

For better exploring the maps, the web application includes a search tool, and an identify tool (Figure 6-9). The search tool allows the user to select data using two different searches: search by ZIP code and search by county. 


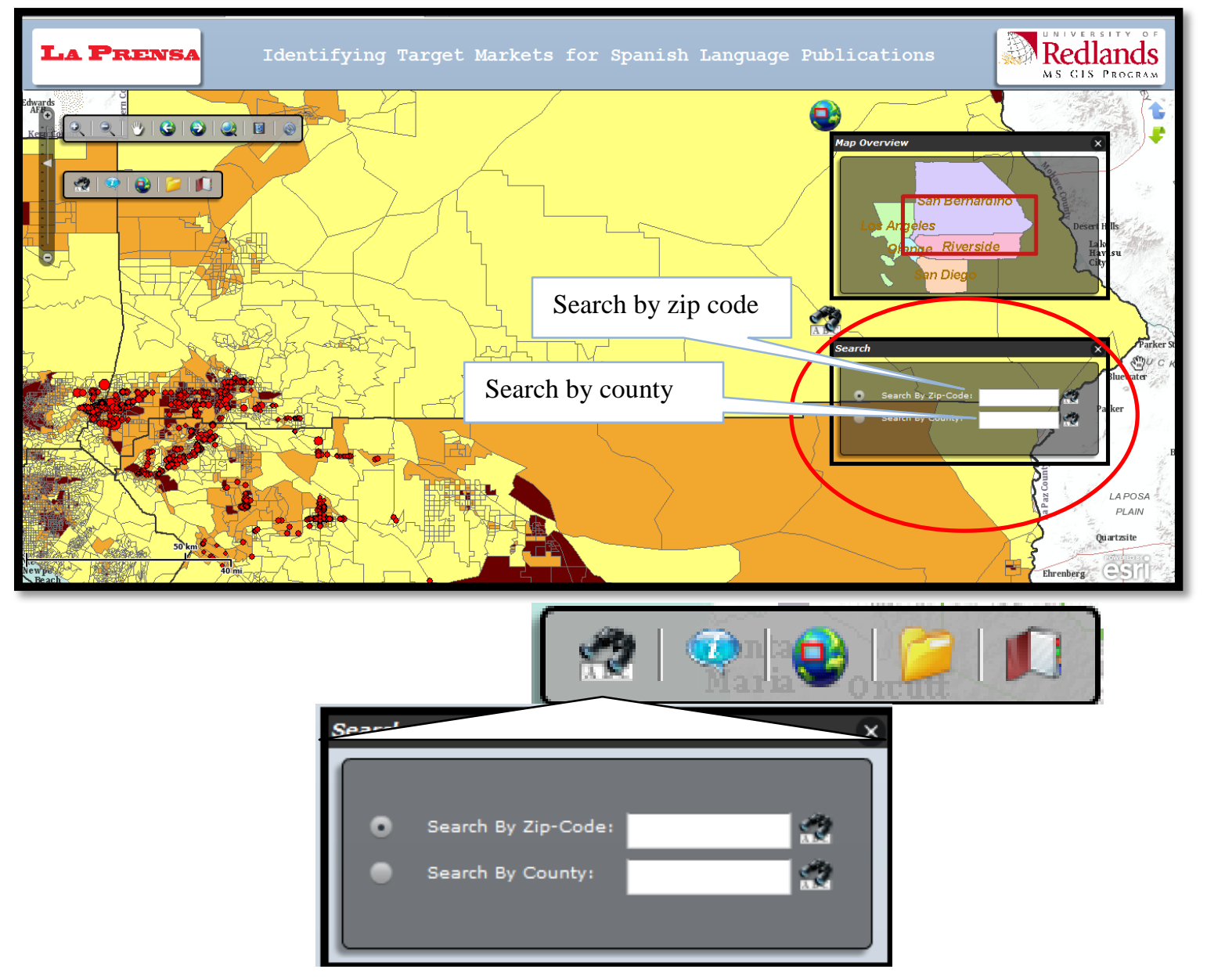

Figure 6-9: Search Tool

The Identify tool allows the user to retrieve information about two types of data: the business name of a La Prensa distribution store, and the block group information from the census block group data. The user can select the location from the map and the application will retrieve the data in a tool tip (Figure 6-10). 


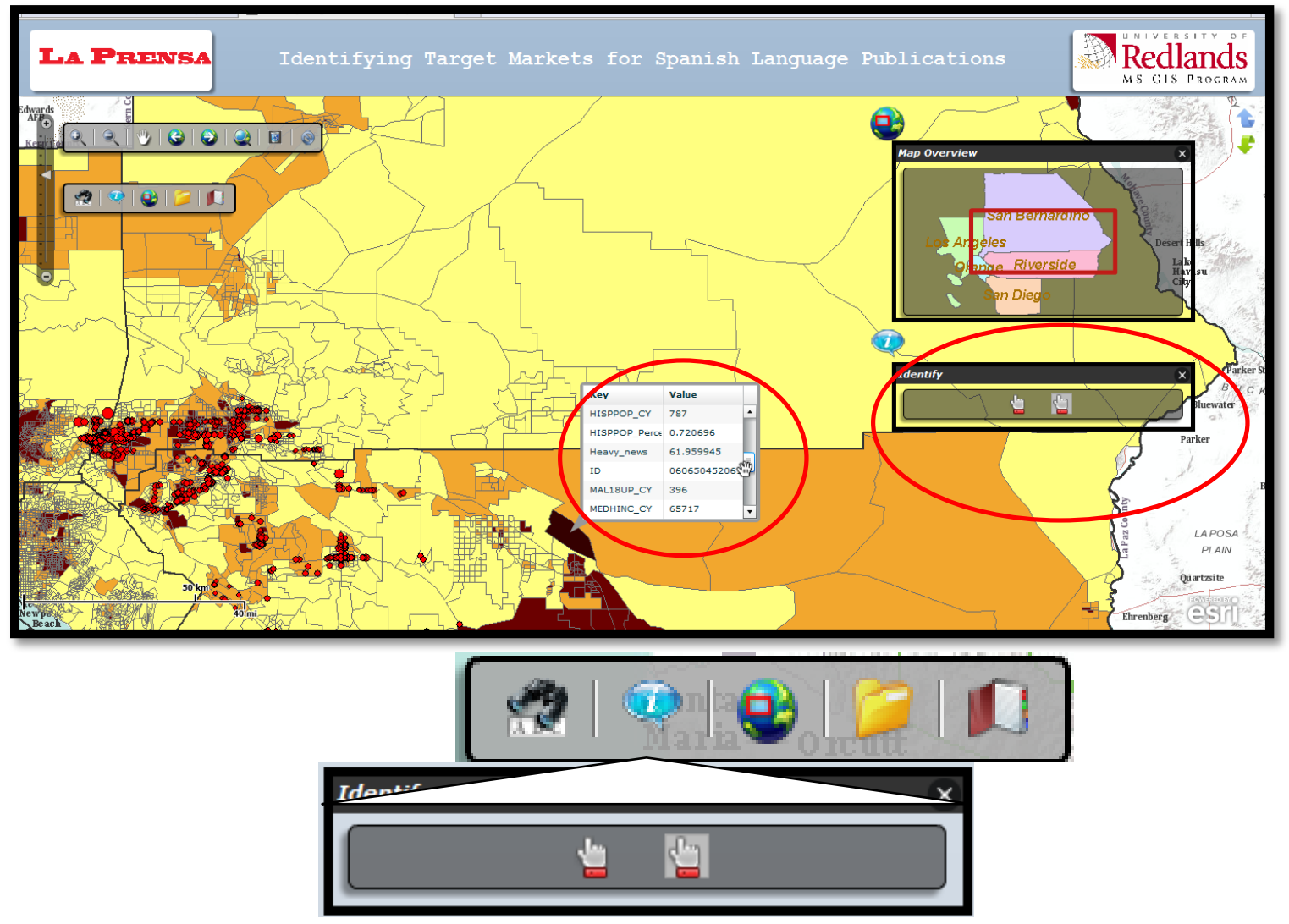

Figure 6-10: Identify Tool and Identify Result

The web application includes a set of navigation tools to let the user interact with maps, such as pan, zoom in, zoom out, full extent, next extent, previous extent. In addition, a transparent tool was added such that the user will be able to control map transparency and view overlaying maps (Figure 6-11). 


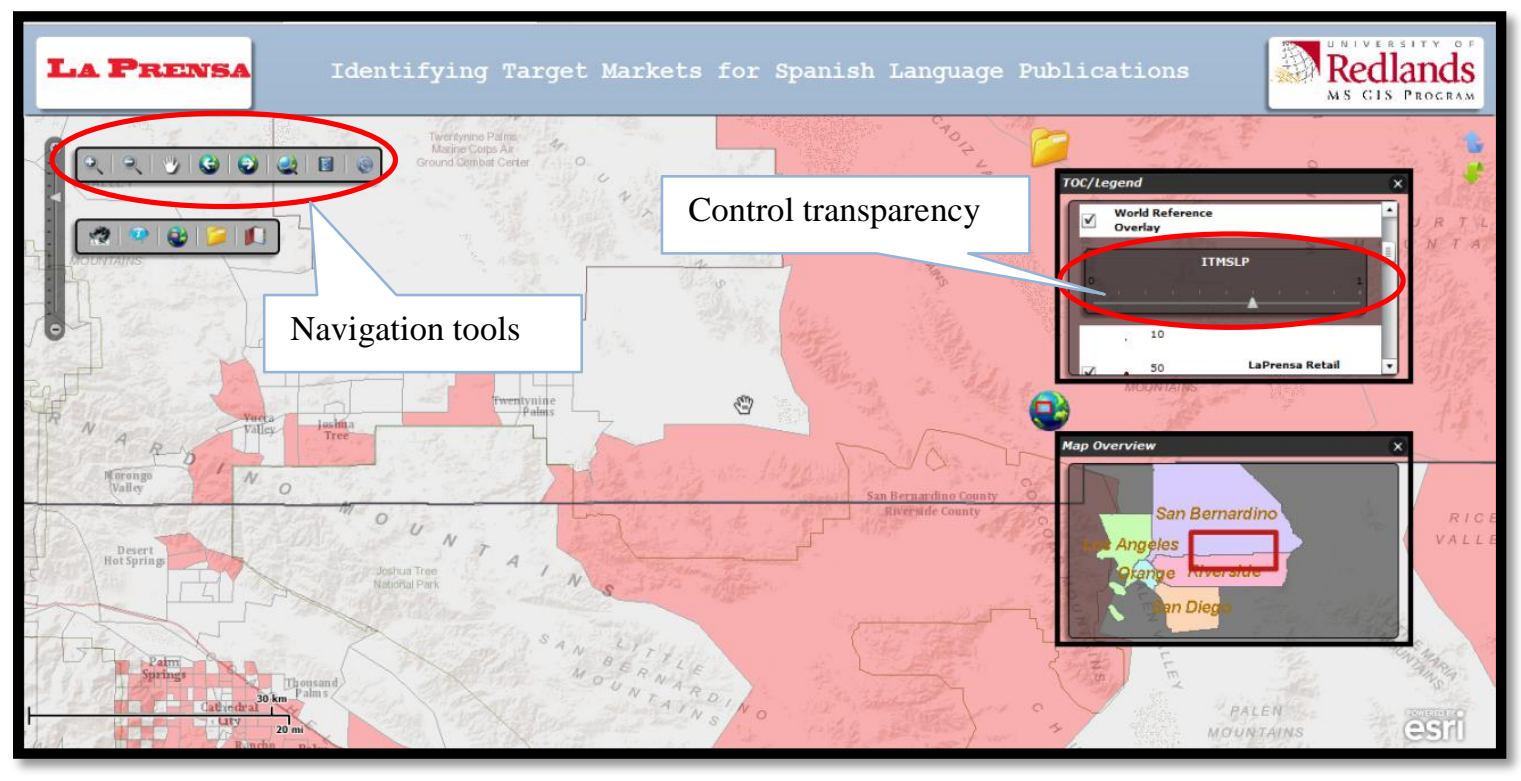

Figure 6-11: Navigation tools and Transparent Tool

\subsection{Summary}

This chapter discussed the results of the different analyses used to analyze the relationship between La Prensa distribution and neighborhoods, as well as the building of the web application. One hundred thirty eight block groups in Riverside County were recommended to be target locations for La Prensa distribution, 2,006 in Los Angeles County, and 256 in San Bernardino County. This recommendation was based on the results of the analyses. The final results were displayed in hardcopy maps and in the web application. The web application contained different functions to allow the user to interact with the different maps. 


\section{Chapter 7 - Conclusions and Future Work}

The main contribution of this project is to identify the neighborhoods where there are Hispanic concentrations. Different analyses were used to estimate the potentials of acceptance of home delivery of the newspaper. Those analyses were adopted to provide the client with a series of analyses to show the trade areas of current newspaper distributors, and to predict the best marketing locations using the demographic data and Tapestry segments. This project also shows the analyses results on maps and allows users to interact with the data and see the final maps in good quality.

\subsection{Find Target Location for La Prensa Distribution Conclusions}

Working with store location points for La Prensa distribution did not contribute much to describing the demographic characteristics for La Prensa customers. This was due to several reasons: the newspaper is a free newspaper that is distributed in random stores with different categories, the customers who pick up La Prensa are not necessarily residents of the same neighborhood, and each store's reputation influences whether potential readers enter the store. However, the different analyses estimated the potential of acceptance of home delivery and, when combined with the existing data, this project shows the strongest demographic variable to define client customer profile and the best marketing locations in the Hispanic population. Block groups that contain high Hispanic concentration are the best target locations to introduce home delivery of La Prensa.

\subsection{Future Work}

Future research should propose variables that could better explain customer profiling for La Prensa and estimate the potential of acceptance of home delivery. The availability of customer data could give better results. This project hypothesizes that the customer will travel five minutes to picks up the newspaper. This could be more predictive if customer locations were provided along with store location data. Study of the land using characteristics, such as whether it is residential or industrial, is also likely be more predictive for home delivery than the different demographics.

For the different maps produced, adding either aerial photos or land use data as a base map would help estimate the number of buildings in each block group. That would give better visualization and estimation of the home delivery and amount of newspapers to be distributed in each block group. In addition, adding one more function to the web application would allow the user to update the store data and add new distribution locations would keep the client updated with the distribution changes. 



\section{Works Cited}

Boyles, D. (2002). GIS Means Business. Redlands: ESRI Press.

Enterprise Media. (2010). PE.com. Retrieved 2010, from www.pe.com:

http://www.pe.com/pe/history.jsp

ESRI. (2003-2008). Using ArcGIS Business Analyst. Redlands: ESRI Press.

ESRI. (2005). ESRI -The Washington Times GIS Increases Newspaper Subscriptions.

Retrieved February 2010, from ESRI Web site:

http://www.esri.com/library/casestudies/washingtontimes.pdf

ESRI. (2009a). Retrieved August 2010, from ESRI We site:

www.esri.com/library/fliers/pdfs/tapestry_segmentation.pdf

ESRI. (2009b). ESRI - The GIS Software Leader| Mapping Software and Data. Retrieved

September 2010, from ESRI Web site:

http://www.esri.com/library/whitepapers/pdfs/esri-data-market-potential.pdf

ESRI. (2009c). Business Analyst Desktop Videos |BADT_DataAggregation102009.

Retrieved October 2010, from ArcGIS Resource Center Web site:

http://resources.arcgis.com/gallery/video/badt

George, L., \& Waldfogel, J. (2003). Who Affects Whom in Daily Newspaper Markets?

The Journal of Political Economy, Vol. 111, No. 4, 765-784.

Herzog, D. (2003). Mapping the News. ESRI Press.

Kazem, A. (2010, August 26). Media Strategic Planner and Demographic Data. (N. Yusuf, Interviewer)

Malthouse, E. C., \& Calder, B. J. (2006). Demographics of Newspaper Readership: Predictors and Patterns of U.S. Consumption. Journal of Media Business Studies, 3(1): 1-18.

Miller, F. L. (2007). GIS Tutorial for Marketing. Redlands: ESRI Press.

Peters, A., \& MacDonald, H. (2004). Unlocking the Census with GIS. Redlands: ESRI Press.

Pick, J. B. (2007). Geo-Business GIS in the Digital Organization. John Wiley \& Sons, Inc.

Project Management Institute. (2004). a Guide to the project Management Body of Knowledge. Newtown Square: Project Management, Inc.

Sarkar, A., \& Greene, R. (2009). University of Redlands. Retrieved May 2010, from business.redlands.edu Web site:

business.redlands.edu/grant/BODAS_Bridal_Magazine.pdf 



\section{Appendix A. Add MPI data}

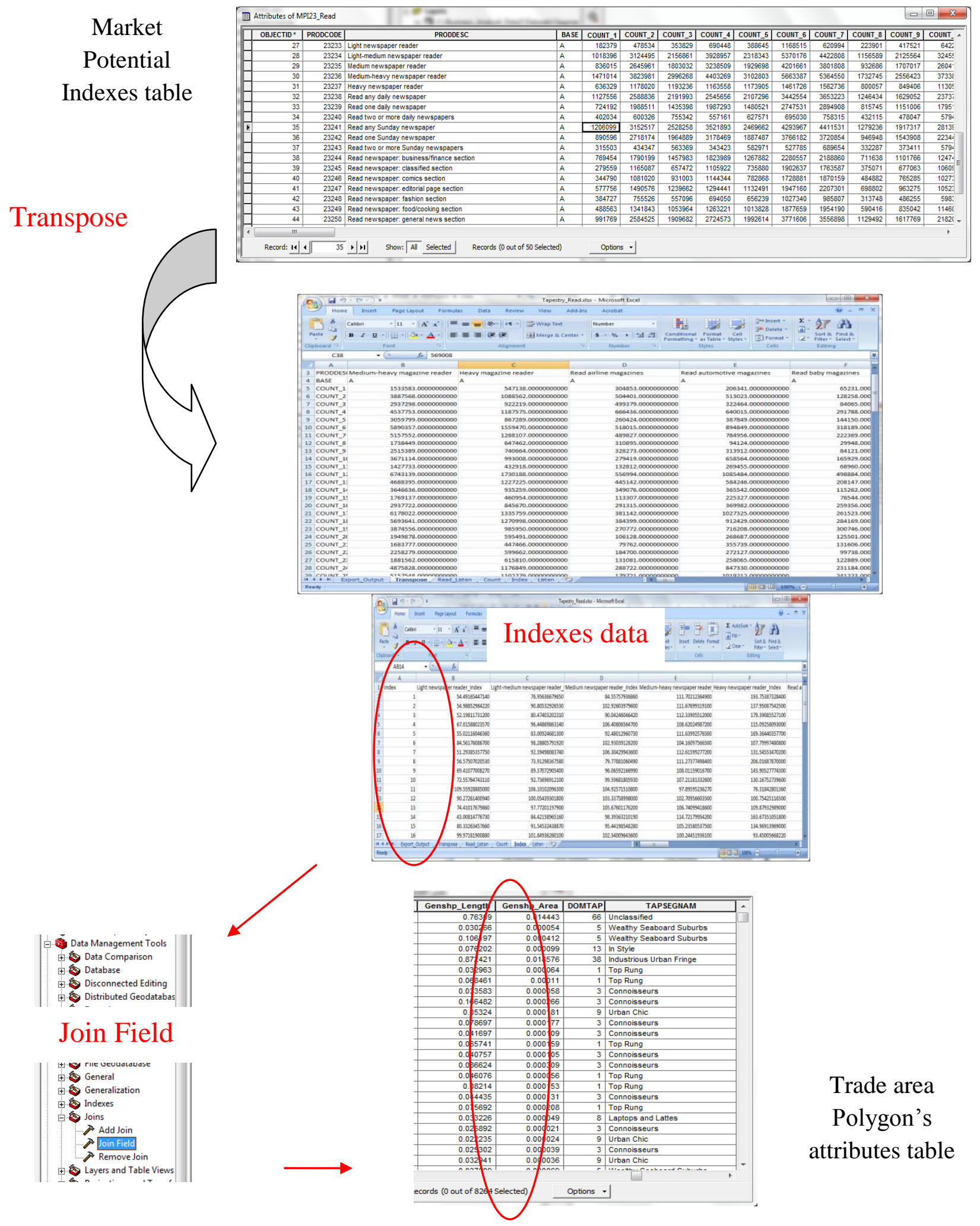




\section{Appendix B. Script codes " Find Multiple Mean Center Iteration Python code and Delete Duplicate Python code \\ 6}

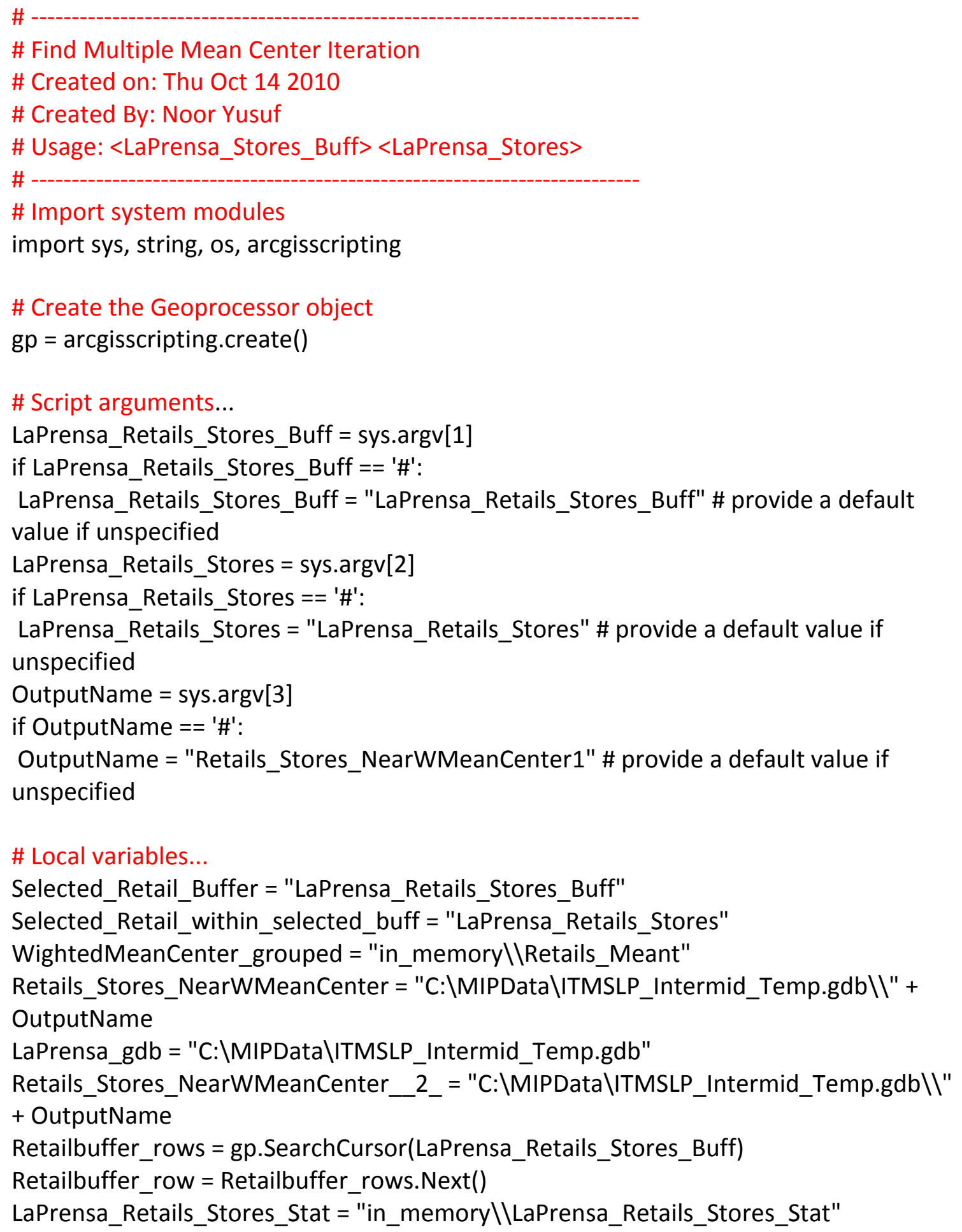


DRAW_Sum = "C:\MIPData\ITMSLP_Intermid_Temp.gdb\IDRAW_Sum"

\# Process: Create Feature Class...

gp.CreateFeatureclass_management(LaPrensa_gdb, OutputName, "POINT",

"C:\\MIPData\\MIP.gdb\\bg_SA_MeanCenter", "DISABLED", "DISABLED",

"GEOGCS['GCS_WGS_1984',DATUM['D_WGS_1984',SPHEROID['WGS_1984',6378137.0,2

98.257223563]],PRIMEM['Greenwich',0.0],UNIT['Degree',0.0174532925199433]];-400 -

400 1000000000;\#;\#;8.98315284119521E-09;\#;\#;IsHighPrecision", "', "0", "0", "0")

\# Process: Create Table...

gp.CreateTable_management(LaPrensa_gdb, "DRAW_Sum",

"C:\\MIPData\\ITMSLP.gdb\\LaPrensa_Retails_Stores_Stat", "')

while Retailbuffer_row:

objid = str (Retailbuffer_row.GetValue('OBJECTID'))

\# Process: Select Layer By Attribute...

gp.SelectLayerByAttribute_management(LaPrensa_Retails_Stores_Buff,

"NEW_SELECTION", "\"OBJECTID\" ="+ objid +"')

\# Process: Select Layer By Location...

gp.SelectLayerByLocation_management(LaPrensa_Retails_Stores,

"COMPLETELY_WITHIN", LaPrensa_Retails_Stores_Buff, "', "NEW_SELECTION")

if gp.GetCount_management(LaPrensa_Retails_Stores) >= 1:

\# Process: Mean Center...

gp.MeanCenter_stats(LaPrensa_Retails_Stores, WightedMeanCenter_grouped, "SUM_SUM_SUM_SUM_SUM_DRAW_1", "', "'")

\# Process: Summary Statistics...

gp.Statistics_analysis(LaPrensa_Retails_Stores, LaPrensa_Retails_Stores_Stat, "SUM_SUM_SUM_SUM_SUM_DRAW_1 SUM", "")

\# Process: Append...

gp.Append_management(LaPrensa_Retails_Stores_Stat, DRAW_Sum, "TEST", "', "')

\# Process: Append...

gp.Append_management(WightedMeanCenter_grouped,

Retails_Stores_NearWMeanCenter, "TEST", "'", "')

Retails_Stores_NearWMeanCenter, "TEST", "'", "')

Retailbuffer_row = Retailbuffer_rows.Next()

\# Process: Join Field... 
gp.JoinField_management(Retails_Stores_NearWMeanCenter, "OBJECTID", DRAW_SUm, "OBJECTID", "FREQUENCY;SUM_SUM_SUM_SUM_SUM_SUM_DRAW_1")

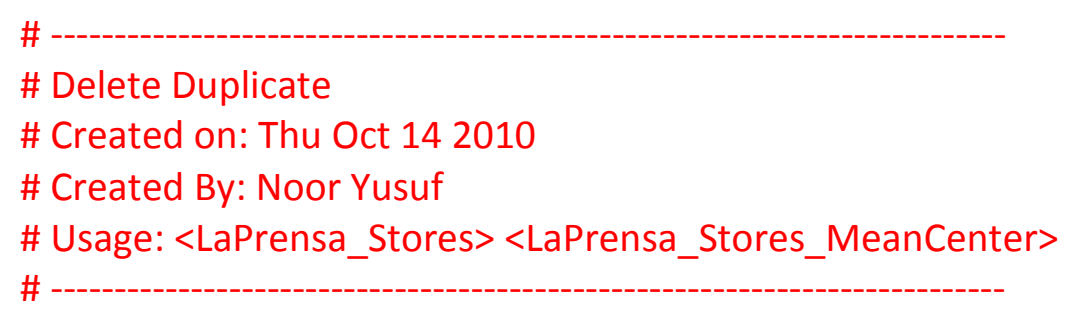




\section{Appendix C. Riverside County Sample of Recommended Block Groups for La Prensa Distribution}

\begin{tabular}{|c|c|c|c|c|}
\hline ID & HISPANIC PERCINTAGE & BLOCK GROUP ID & BLOCK GROUP NAME & STATE NAME \\
\hline 1 & $66.3 \%$ & 060650403012 & 060650403.012 & California \\
\hline 2 & $66.6 \%$ & 060650462001 & 060650462.001 & California \\
\hline 3 & $66.7 \%$ & 060650425052 & 060650425.052 & California \\
\hline 4 & $66.8 \%$ & 060650405021 & 060650405.021 & California \\
\hline 5 & $66.8 \%$ & 060650436004 & 060650436.004 & California \\
\hline 6 & $66.9 \%$ & 060650406062 & 060650406.062 & California \\
\hline 7 & $67.1 \%$ & 060650413001 & 060650413.001 & California \\
\hline 8 & $67.2 \%$ & 060650301003 & 060650301.003 & California \\
\hline 9 & $67.4 \%$ & 060650461021 & 060650461.021 & California \\
\hline 10 & $67.4 \%$ & 060650402011 & 060650402.011 & California \\
\hline 11 & $67.6 \%$ & 060650429032 & 060650429.032 & California \\
\hline 12 & $67.7 \%$ & 060650413003 & 060650413.003 & California \\
\hline 13 & $67.7 \%$ & 060650305013 & 060650305.013 & California \\
\hline 14 & $67.9 \%$ & 060650406061 & 060650406.061 & California \\
\hline 15 & $68.0 \%$ & 060650413002 & 060650413.002 & California \\
\hline 16 & $68.0 \%$ & 060650419091 & 060650419.091 & California \\
\hline 17 & $68.1 \%$ & 060650404033 & 060650404.033 & California \\
\hline 18 & $68.2 \%$ & 060650425151 & 060650425.151 & California \\
\hline 19 & $68.2 \%$ & 060650404031 & 060650404.031 & California \\
\hline 20 & $68.3 \%$ & 060650411005 & 060650411.005 & California \\
\hline 21 & $68.4 \%$ & 060650426031 & 060650426.031 & California \\
\hline 22 & $68.5 \%$ & 060650436002 & 060650436.002 & California \\
\hline 23 & $68.6 \%$ & 060650317011 & 060650317.011 & California \\
\hline 24 & $68.7 \%$ & 060650440002 & 060650440.002 & California \\
\hline 25 & $68.7 \%$ & 060650420093 & 060650420.093 & California \\
\hline 26 & $68.8 \%$ & 060650425081 & 060650425.081 & California \\
\hline 27 & $69.2 \%$ & 060650301001 & 060650301.001 & California \\
\hline 28 & $69.2 \%$ & 060650417031 & 060650417.031 & California \\
\hline 29 & $69.4 \%$ & 060650452072 & 060650452.072 & California \\
\hline 30 & $69.9 \%$ & 060650405022 & 060650405.022 & California \\
\hline 31 & $70.5 \%$ & 060650436001 & 060650436.001 & California \\
\hline 32 & $70.6 \%$ & 060650451113 & 060650451.113 & California \\
\hline 33 & $70.6 \%$ & 060650419062 & 060650419.062 & California \\
\hline 34 & $70.7 \%$ & 060650414092 & 060650414.092 & California \\
\hline 35 & $70.9 \%$ & 060650410011 & 060650410.011 & California \\
\hline 36 & $71.3 \%$ & 060650425041 & 060650425.041 & California \\
\hline 37 & $71.4 \%$ & 060650305012 & 060650305.012 & California \\
\hline 38 & $71.5 \%$ & 060650411004 & 060650411.004 & California \\
\hline 39 & $71.5 \%$ & 060650317041 & 060650317.041 & California \\
\hline 40 & $71.6 \%$ & 060650401003 & 060650401.003 & California \\
\hline 41 & $71.7 \%$ & 060650406052 & 060650406.052 & California \\
\hline
\end{tabular}




\begin{tabular}{|c|c|c|c|c|}
\hline ID & HISPANIC PERCINTAGE & BLOCK GROUP ID & BLOCK GROUP NAME & STATE NAME \\
\hline 42 & $72.1 \%$ & 060650406051 & 060650406.051 & California \\
\hline 43 & $72.1 \%$ & 060650452061 & 060650452.061 & California \\
\hline 92 & $85.5 \%$ & 060650411002 & 060650411.002 & California \\
\hline 93 & $85.5 \%$ & 060650402031 & 060650402.031 & California \\
\hline 94 & $85.6 \%$ & 060650452091 & 060650452.091 & California \\
\hline 95 & $85.9 \%$ & 060650455022 & 060650455.022 & California \\
\hline 96 & $86.1 \%$ & 060650414112 & 060650414.112 & California \\
\hline 97 & $86.8 \%$ & 060650416001 & 060650416.001 & California \\
\hline 98 & $86.9 \%$ & 060650455012 & 060650455.012 & California \\
\hline 99 & $87.3 \%$ & 060650305021 & 060650305.021 & California \\
\hline 100 & $87.4 \%$ & 060650456034 & 060650456.034 & California \\
\hline 101 & $87.6 \%$ & 060650305032 & 060650305.032 & California \\
\hline 102 & $88.1 \%$ & 060650305031 & 060650305.031 & California \\
\hline 103 & $88.2 \%$ & 060650415002 & 060650415.002 & California \\
\hline 104 & $88.7 \%$ & 060650416004 & 060650416.004 & California \\
\hline 105 & $88.8 \%$ & 060650415001 & 060650415.001 & California \\
\hline 106 & $89.4 \%$ & 060650417042 & 060650417.042 & California \\
\hline 107 & $89.4 \%$ & 060650305022 & 060650305.022 & California \\
\hline 108 & $89.5 \%$ & 060650304005 & 060650304.005 & California \\
\hline 109 & $89.9 \%$ & 060650450004 & 060650450.004 & California \\
\hline 110 & $90.3 \%$ & 060650455011 & 060650455.011 & California \\
\hline 111 & $90.6 \%$ & 060650453021 & 060650453.021 & California \\
\hline 112 & $91.1 \%$ & 060650416003 & 060650416.003 & California \\
\hline 113 & $91.2 \%$ & 060650453011 & 060650453.011 & California \\
\hline 114 & $91.3 \%$ & 060650313001 & 060650313.001 & California \\
\hline 115 & $91.8 \%$ & 060650454002 & 060650454.002 & California \\
\hline 116 & $92.2 \%$ & 060650456051 & 060650456.051 & California \\
\hline 117 & $92.3 \%$ & 060650452071 & 060650452.071 & California \\
\hline 118 & $92.4 \%$ & 060650453022 & 060650453.022 & California \\
\hline 119 & $93.0 \%$ & 060650453023 & 060650453.023 & California \\
\hline 120 & $93.2 \%$ & 060650453012 & 060650453.012 & California \\
\hline 121 & $94.0 \%$ & 060650313003 & 060650313.003 & California \\
\hline 122 & $94.7 \%$ & 060650414101 & 060650414.101 & California \\
\hline 123 & $95.2 \%$ & 060650414102 & 060650414.102 & California \\
\hline 124 & $95.6 \%$ & 060650313002 & 060650313.002 & California \\
\hline 125 & $95.7 \%$ & 060650456052 & 060650456.052 & California \\
\hline 126 & $96.0 \%$ & 060650456042 & 060650456.042 & California \\
\hline 127 & $96.1 \%$ & 060650454001 & 060650454.001 & California \\
\hline 128 & $96.3 \%$ & 060650456031 & 060650456.031 & California \\
\hline 129 & $96.4 \%$ & 060650456032 & 060650456.032 & California \\
\hline 130 & $96.9 \%$ & 060650457022 & 060650457.022 & California \\
\hline 131 & $97.1 \%$ & 060650454003 & 060650454.003 & California \\
\hline 132 & $97.2 \%$ & 060650456041 & 060650456.041 & California \\
\hline 133 & $97.7 \%$ & 060650457023 & 060650457.023 & California \\
\hline 134 & $97.8 \%$ & 060650457062 & 060650457.062 & California \\
\hline 135 & $98.0 \%$ & 060650457041 & 060650457.041 & California \\
\hline 136 & $98.1 \%$ & 060650457021 & 060650457.021 & California \\
\hline 137 & $98.2 \%$ & 060650457031 & 060650457.031 & California \\
\hline
\end{tabular}




\section{Appendix D. Los Angeles County Sample of Recommended Block Groups for La Prensa Distribution}

\begin{tabular}{|c|c|c|c|c|}
\hline ID & HISPANIC PERCINTAGE & CK GROUP ID & BLOCK GROUP NAME & STATE NAME \\
\hline 1 & $65.8 \%$ & 060375515001 & 060375515.001 & California \\
\hline 2 & $65.9 \%$ & 060372226002 & 060372226.002 & California \\
\hline 3 & $65.9 \%$ & 060375755004 & 060375755.004 & California \\
\hline 4 & $65.9 \%$ & 060375551042 & 060375551.042 & California \\
\hline 5 & $65.9 \%$ & 060371253202 & 060371253.202 & California \\
\hline 6 & $65.9 \%$ & 060371096011 & 060371096.011 & California \\
\hline 7 & $66.0 \%$ & 060372413001 & 060372413.001 & California \\
\hline 8 & $66.0 \%$ & 060371912031 & 060371912.031 & California \\
\hline 9 & $66.0 \%$ & 060374331002 & 060374331.002 & California \\
\hline 10 & $66.0 \%$ & 060375406001 & 060375406.001 & California \\
\hline 11 & $66.0 \%$ & 060375541023 & 060375541.023 & California \\
\hline 12 & $66.0 \%$ & 060371973004 & 060371973.004 & California \\
\hline 13 & $66.0 \%$ & 060375300062 & 060375300.062 & California \\
\hline 14 & $66.0 \%$ & 060375425021 & 060375425.021 & California \\
\hline 15 & $66.0 \%$ & 060372405001 & 060372405.001 & California \\
\hline 16 & $66.1 \%$ & 060375519002 & 060375519.002 & California \\
\hline 17 & $66.1 \%$ & 060374311003 & 060374311.003 & California \\
\hline 18 & $66.1 \%$ & 060371909023 & 060371909.023 & California \\
\hline 19 & $66.1 \%$ & 060375033021 & 060375033.021 & California \\
\hline 20 & $66.1 \%$ & 060371834002 & 060371834.002 & California \\
\hline 21 & $66.2 \%$ & 060372182202 & 060372182.202 & California \\
\hline 22 & $66.2 \%$ & 060372696002 & 060372696.002 & California \\
\hline 23 & $66.2 \%$ & 060376041001 & 060376041.001 & California \\
\hline 24 & $66.2 \%$ & 060375425022 & 060375425.022 & California \\
\hline 25 & $66.2 \%$ & 060372181203 & 060372181.203 & California \\
\hline 26 & $66.2 \%$ & 060372408001 & 060372408.001 & California \\
\hline 27 & $66.2 \%$ & 060371273002 & 060371273.002 & California \\
\hline 28 & $66.2 \%$ & 060372313003 & 060372313.003 & California \\
\hline 29 & $66.3 \%$ & 060374326014 & 060374326.014 & California \\
\hline 30 & $66.3 \%$ & 060375422001 & 060375422.001 & California \\
\hline 31 & $66.3 \%$ & 060375035011 & 060375035.011 & California \\
\hline 32 & $66.3 \%$ & 060375521003 & 060375521.003 & California \\
\hline 33 & $66.3 \%$ & 060372188001 & 060372188.001 & California \\
\hline 34 & $66.3 \%$ & 060371234102 & 060371234.102 & California \\
\hline 35 & $66.3 \%$ & 060375514005 & 060375514.005 & California \\
\hline 36 & $66.3 \%$ & 060376039001 & 060376039.001 & California \\
\hline 37 & $66.3 \%$ & 060374811034 & 060374811.034 & California \\
\hline 38 & $66.4 \%$ & 060372414004 & 060372414.004 & California \\
\hline 39 & $66.4 \%$ & 060371219001 & 060371219.001 & California \\
\hline 40 & $66.4 \%$ & 060371218002 & 060371218.002 & California \\
\hline 41 & $66.4 \%$ & 060372911302 & 060372911.302 & California \\
\hline 42 & $66.4 \%$ & 060375753002 & 060375753.002 & California \\
\hline 43 & $66.4 \%$ & 060375032011 & 060375032.011 & California \\
\hline
\end{tabular}




\begin{tabular}{|c|c|c|c|c|}
\hline ID & HISPANIC PERCINTAGE & CK GROUP ID & BLOCK GROUP NAME & STATE NAME \\
\hline 1963 & $98.3 \%$ & 060375023012 & 060375023.012 & California \\
\hline 1964 & $98.4 \%$ & 060372047003 & 060372047.003 & California \\
\hline 1965 & $98.4 \%$ & 060372031002 & 060372031.002 & California \\
\hline 1966 & $98.4 \%$ & 060375313026 & 060375313.026 & California \\
\hline 1967 & $98.4 \%$ & 060372048201 & 060372048.201 & California \\
\hline 1968 & $98.4 \%$ & 060375315013 & 060375315.013 & California \\
\hline 1969 & $98.4 \%$ & 060375310006 & 060375310.006 & California \\
\hline 1970 & $98.4 \%$ & 060375311021 & 060375311.021 & California \\
\hline 1971 & $98.4 \%$ & 060375333002 & 060375333.002 & California \\
\hline 1972 & $98.4 \%$ & 060375312023 & 060375312.023 & California \\
\hline 1973 & $98.4 \%$ & 060372051101 & 060372051.101 & California \\
\hline 1974 & $98.5 \%$ & 060375310008 & 060375310.008 & California \\
\hline 1975 & $98.5 \%$ & 060375332011 & 060375332.011 & California \\
\hline 1976 & $98.5 \%$ & 060375316041 & 060375316.041 & California \\
\hline 1977 & $98.5 \%$ & 060372041103 & 060372041.103 & California \\
\hline 1978 & $98.5 \%$ & 060372048102 & 060372048.102 & California \\
\hline 1979 & $98.5 \%$ & 060375331041 & 060375331.041 & California \\
\hline 1980 & $98.5 \%$ & 060375311022 & 060375311.022 & California \\
\hline 1981 & $98.5 \%$ & 060375337021 & 060375337.021 & California \\
\hline 1982 & $98.5 \%$ & 060375305001 & 060375305.001 & California \\
\hline 1983 & $98.5 \%$ & 060375311012 & 060375311.012 & California \\
\hline 1984 & $98.5 \%$ & 060375315012 & 060375315.012 & California \\
\hline 1985 & $98.5 \%$ & 060375331031 & 060375331.031 & California \\
\hline 1986 & $98.5 \%$ & 060375331032 & 060375331.032 & California \\
\hline 1987 & $98.5 \%$ & 060372036003 & 060372036.003 & California \\
\hline 1988 & $98.5 \%$ & 060375316023 & 060375316.023 & California \\
\hline 1989 & $98.5 \%$ & 060372032002 & 060372032.002 & California \\
\hline 1990 & $98.6 \%$ & 060375313024 & 060375313.024 & California \\
\hline 1991 & $98.6 \%$ & 060375327001 & 060375327.001 & California \\
\hline 1992 & $98.6 \%$ & 060375305003 & 060375305.003 & California \\
\hline 1993 & $98.6 \%$ & 060375316022 & 060375316.022 & California \\
\hline 1994 & $98.6 \%$ & 060375307002 & 060375307.002 & California \\
\hline 1995 & $98.6 \%$ & 060372037202 & 060372037.202 & California \\
\hline 1996 & $98.6 \%$ & 060372242001 & 060372242.001 & California \\
\hline 1997 & $98.6 \%$ & 060375313025 & 060375313.025 & California \\
\hline 1998 & $98.6 \%$ & 060375316032 & 060375316.032 & California \\
\hline 1999 & $98.6 \%$ & 060375309011 & 060375309.011 & California \\
\hline 2000 & $98.7 \%$ & 060375323024 & 060375323.024 & California \\
\hline 2001 & $98.7 \%$ & 060375332012 & 060375332.012 & California \\
\hline 2002 & $98.7 \%$ & 060375334013 & 060375334.013 & California \\
\hline 2003 & $98.7 \%$ & 060375327002 & 060375327.002 & California \\
\hline 2004 & $98.7 \%$ & 060375313027 & 060375313.027 & California \\
\hline 2005 & $98.7 \%$ & 060375315017 & 060375315.017 & California \\
\hline 2006 & $98.8 \%$ & 060375313012 & 060375313.012 & California \\
\hline
\end{tabular}




\section{Appendix E. San Bernardino County Sample of Recommended Block Groups for La Prensa Distribution}

\begin{tabular}{|c|c|c|c|c|}
\hline ID & HISPANIC PERCINTAGE & BLOCK GROUP ID & BLOCK GROUP NAME & STATE NAME \\
\hline 1 & $66.0 \%$ & 060710036021 & 060710036.021 & California \\
\hline 2 & $66.0 \%$ & 060710018021 & 060710018.021 & California \\
\hline 3 & $66.3 \%$ & 060710036011 & 060710036.011 & California \\
\hline 4 & $66.3 \%$ & 060710003012 & 060710003.012 & California \\
\hline 5 & $66.5 \%$ & 060710037002 & 060710037.002 & California \\
\hline 6 & $66.5 \%$ & 060710030002 & 060710030.002 & California \\
\hline 7 & $66.5 \%$ & 060710036014 & 060710036.014 & California \\
\hline 8 & $66.6 \%$ & 060710033007 & 060710033.007 & California \\
\hline 9 & $66.8 \%$ & 060710003033 & 060710003.033 & California \\
\hline 10 & $66.9 \%$ & 060710035016 & 060710035.016 & California \\
\hline 11 & $66.9 \%$ & 060710002026 & 060710002.026 & California \\
\hline 12 & $67.1 \%$ & 060710033008 & 060710033.008 & California \\
\hline 13 & $67.2 \%$ & 060710032002 & 060710032.002 & California \\
\hline 14 & $67.3 \%$ & 060710080011 & 060710080.011 & California \\
\hline 15 & $67.3 \%$ & 060710058001 & 060710058.001 & California \\
\hline 16 & $67.4 \%$ & 060710034026 & 060710034.026 & California \\
\hline 17 & $67.4 \%$ & 060710072002 & 060710072.002 & California \\
\hline 18 & $67.4 \%$ & 060710022041 & 060710022.041 & California \\
\hline 19 & $67.5 \%$ & 060710044012 & 060710044.012 & California \\
\hline 20 & $67.5 \%$ & 060710001125 & 060710001.125 & California \\
\hline 21 & $67.6 \%$ & 060710036023 & 060710036.023 & California \\
\hline 22 & $67.6 \%$ & 060710035011 & 060710035.011 & California \\
\hline 23 & $67.7 \%$ & 060710044022 & 060710044.022 & California \\
\hline 24 & $67.7 \%$ & 060710094002 & 060710094.002 & California \\
\hline 25 & $67.7 \%$ & 060710023011 & 060710023.011 & California \\
\hline 26 & $67.9 \%$ & 060710026012 & 060710026.012 & California \\
\hline 27 & $68.1 \%$ & 060710026032 & 060710026.032 & California \\
\hline 28 & $68.2 \%$ & 060710034014 & 060710034.014 & California \\
\hline 29 & $68.3 \%$ & 060710034032 & 060710034.032 & California \\
\hline 30 & $68.4 \%$ & 060710033001 & 060710033.001 & California \\
\hline 31 & $68.4 \%$ & 060710002027 & 060710002.027 & California \\
\hline 32 & $68.5 \%$ & 060710023014 & 060710023.014 & California \\
\hline 33 & $68.5 \%$ & 060710080024 & 060710080.024 & California \\
\hline 34 & $68.6 \%$ & 060710003013 & 060710003.013 & California \\
\hline 35 & $68.7 \%$ & 060710055001 & 060710055.001 & California \\
\hline 36 & $68.7 \%$ & 060710035026 & 060710035.026 & California \\
\hline 37 & $68.8 \%$ & 060710056003 & 060710056.003 & California \\
\hline 38 & $68.8 \%$ & 060710015001 & 060710015.001 & California \\
\hline 39 & $68.9 \%$ & 060710013011 & 060710013.011 & California \\
\hline 40 & $68.9 \%$ & 060710026031 & 060710026.031 & California \\
\hline 41 & $69.0 \%$ & 060710018015 & 060710018.015 & California \\
\hline 42 & $69.1 \%$ & 060710002013 & 060710002.013 & California \\
\hline 43 & $69.3 \%$ & 060710002024 & 060710002.024 & California \\
\hline
\end{tabular}




\begin{tabular}{|lrlll|}
\hline \multicolumn{1}{|l}{ ID } & HISPANIC PERCINTAGE & BLOCK GROUP ID & BLOCK GROUP NAME & STATE NAME \\
$\mathbf{2 3 6}$ & $91.3 \%$ & 060710016006 & 060710016.006 & California \\
\hline $\mathbf{2 3 7}$ & $91.4 \%$ & 060710067001 & 060710067.001 & California \\
\hline $\mathbf{2 3 8}$ & $91.7 \%$ & 060710006021 & 060710006.021 & California \\
\hline $\mathbf{2 3 9}$ & $92.0 \%$ & 060710016002 & 060710016.002 & California \\
\hline $\mathbf{2 4 0}$ & $92.1 \%$ & 060710018014 & 060710018.014 & California \\
\hline $\mathbf{2 4 1}$ & $92.5 \%$ & 060710059002 & 060710059.002 & California \\
\hline $\mathbf{2 4 2}$ & $92.7 \%$ & 060710067002 & 060710067.002 & California \\
\hline $\mathbf{2 4 3}$ & $92.8 \%$ & 060710005007 & 060710005.007 & California \\
\hline $\mathbf{2 4 4}$ & $93.6 \%$ & 060710015002 & 060710015.002 & California \\
\hline $\mathbf{2 4 5}$ & $94.6 \%$ & 060710016005 & 060710016.005 & California \\
\hline $\mathbf{2 4 6}$ & $94.7 \%$ & 060710016003 & 060710016.003 & California \\
\hline $\mathbf{2 4 7}$ & $94.7 \%$ & 060710049005 & 060710049.005 & California \\
\hline $\mathbf{2 4 8}$ & $94.7 \%$ & 060710069004 & 060710069.004 & California \\
\hline $\mathbf{2 4 9}$ & $95.0 \%$ & 060710021006 & 060710021.006 & California \\
\hline $\mathbf{2 5 0}$ & $95.2 \%$ & 060710069005 & 060710069.005 & California \\
\hline $\mathbf{2 5 1}$ & $95.2 \%$ & 060710069001 & 060710069.001 & California \\
\hline $\mathbf{2 5 2}$ & $95.5 \%$ & 060710069003 & 060710069.003 & California \\
\hline $\mathbf{2 5 3}$ & $95.9 \%$ & 060710018016 & 060710018.016 & California \\
\hline $\mathbf{2 5 4}$ & $95.9 \%$ & 060710016004 & 060710016.004 & California \\
\hline $\mathbf{2 5 5}$ & $96.4 \%$ & 060710048004 & 060710048.004 & California \\
\hline $\mathbf{2 5 6}$ & $96.6 \%$ & 060710048003 & 060710048.003 & California \\
\hline
\end{tabular}

